\title{
Uncertain Productivity Growth and the Choice between FDI and Export
}

\author{
Erdal Yalcin
}

CESIFO WORKING PAPER NO. 2773

CATEgOry 8: TRAde Policy

AUGUST 2009

Presented at CESifo Venice Summer Institute, July 2009

\footnotetext{
An electronic version of the paper may be downloaded

- from the SSRN website:

- from the RePEc website: www.SSRN.com

Www.RePEc.org

- from the CESifo website:

www.CESifo-group.org/wp
} 


\title{
Uncertain Productivity Growth and the Choice between FDI and Export
}

\begin{abstract}
The underlying model analyzes the first time foreign market entry decision of a representative investor who can choose between export and FDI. The model combines the proximityconcentration trade-off framework with the real option methodology and sheds light on the effects of productivity growth. On the basis of a Geometric Brownian motion, three different productivity scenarios are considered (no growth, deterministic growth, uncertain growth) and opposed to each other. The introduction of productivity growth increases the likeliness of first time market entry through FDI. If the firm is confronted with uncertain productivity growth, market entry through FDI increases even further. Uncertainty is identified as a compounding force for the derived growth effects. The findings contribute to the static general equilibrium models which neglect intertemporal selection effects.
\end{abstract}

JEL Code: F17, F21, F23.

Keywords: export, FDI, uncertain productivity growth, real option approach.

\author{
Erdal Yalcin \\ Chair in International Economics \\ Eberhard Karls University \\ Nauklerstrasse 47 \\ 72074 Tübingen \\ Germany \\ Erdal.Yalcin@uni-tuebingen.de
}

July 2009

I would like to thank Wilhelm Kohler who supported my research in ample ways. Furthermore, I am profoundly indebted to Davide Sala, who provided invaluable comments. Thanks are due to Philipp Schröder for inviting me to Denmark, where I developed my basic ideas further. I have benefited from comments of participants on the CESifo Summer Institute Conference "Operating Uncertainty Using Real Options". In particular, I thank Giuseppe Bertola and Thomas Gries. I am grateful for CESifo's financial sponsorship. 


\section{Introduction}

The explanation of international economic integration has been a core field of economic research for decades. Development and welfare disparities between countries (regions) have been analyzed empirically and theoretically, whereas in both disciplines trade has been considered as the balancing force between unbalanced economic entities. Until the late 70s two major theoretical frameworks have dominated the analysis of international trade in goods. According to the Ricardian models (see e.g. Dornbusch et al., 1977), countries are involved into trade due to differences in their production technologies, and through trade in goods, they can improve their welfare state (gains from trade). The second influential explanation for observed goods flows has been the Heckscher-Ohlin framework according to which countries trade due to different relative endowments (see e.g. Heckscher and Ohlin, 1991). Within these commonly accepted and widespread models, international trade is motivated by comparative advantages either in technologies or in relative factor endowments. However, in none of these concepts the firm as a microeconomic entity plays a role, since differences are analyzed on the basis of sectors. This negligence of firm behavior both empirically and theoretically can be partly explained by the simple unavailability of appropriate data at the time of the model creation.

However, with the 1970s the perception of global economic integration has started to change. Besides the steady growth of international trade flows (averagely 5.6\%), economists recognized the extraordinary surge in global investment behavior of multinational enterprises. Starting in the late 1970s foreign direct investments (FDI) have shown an average annual growth rate of 17.7\% until 2000 (Navaretti and Venables, 2004). The rising awareness of multinational investment behavior incited a dogmatic change in the theoretical explanation of international economic integration. The first seminal work which introduces firm behavior into the trade context has been presented by Krugman (1979). In his so-called New-Trade Theory, firms are modeled in a Dixit-Stiglitz framework and represent the source of international trade due to increasing returns to scale technologies. Within this first generation of monopolistic competition models, firm heterogeneity does not play a role since the major objective has been the explanation of intraindustry trade as such, which was not explicable within the classical models (Krugman, 1980). In the Krugman Model all firms export once trade is introduced.

Sensitized by the New-Trade theory and due to the increasing availability of commensurate data about international firm behavior, a broad range of various theoretical and empirical analyses 
with a stronger focus on multinational enterprises emerged in the 1980s. Besides the attempt to explain more complex export patterns, FDI started to be implemented into the new theoretical frameworks. Among them are Horstman and Markusen (1987), Markusen and Venables (1998, 2000), Brainard (1993), Helpman (1984, 1985), Ethier and Markusen (1996), and Ehtier (1986). A common ground within these models is the elaboration of the relationship between fixed and variable costs as one fundamental determinant, whether a firm starts to export or becomes a foreign direct investor (horizontal FDI). One specific assumption about the cost structure of firms and the resulting international firm behavior has been summarized as the proximity-concentration trade-off framework (Brainard 1993, 1997). Within this framework, firms are considered to be confronted with higher fixed costs in the FDI mode relative to the export mode, if they intend to enter a new market. Due to the fixed costs, firms possess increasing returns to scale in both market entry strategies. Simultaneously the export mode is assumed to exhibit higher variable costs relative to the FDI strategy since transport costs and other barriers add to the domestic production costs. As a result, the extent of scale effects in the two entry modes differ with respect to the state variables (quantity, goods price, productivity etc.). A strong significance of the proximity-concentration trade-off framework has been depicted empirically by Brainard (1997) for 27 countries on the industry level. Since then, the proximity-concentration hypothesis, as it is also referred to, has been established as a workhorse which explains export and FDI patterns. The latest theoretical breakthrough in explaining the international firm behavior has been achieved by the so called New New Trade Theories, based on the seminal work of Melitz (2003), which was extended by Helpman et al. in 2004. Since empirical studies from the 1990s (Bernhard and Jensen, 1995; Doms and Jensen, 1998) and subsequently point out that differences in firm productivity lead to a firm distribution within an industry, in which not all firms export or become foreign direct investors (Greenaway and Kneller, 2007), the New Trade Theory appears to be limited for deeper explanation. Helpman et al. (2004) give consideration to these new empirical insights by introducing firm heterogeneity within an industry. The authors overcome the limitation of the standard monopolistic competition models (symmetric firms within a sector) by introducing the proximity-concentration hypothesis and by implementing productivity uncertainty. Figure 1 demonstrates the common result of this literature strand in which the most productive firms within a sector will be foreign direct investors, less productive ones will export and the least productive ones will serve only the home market conditional on survival. The sector-specific firm 


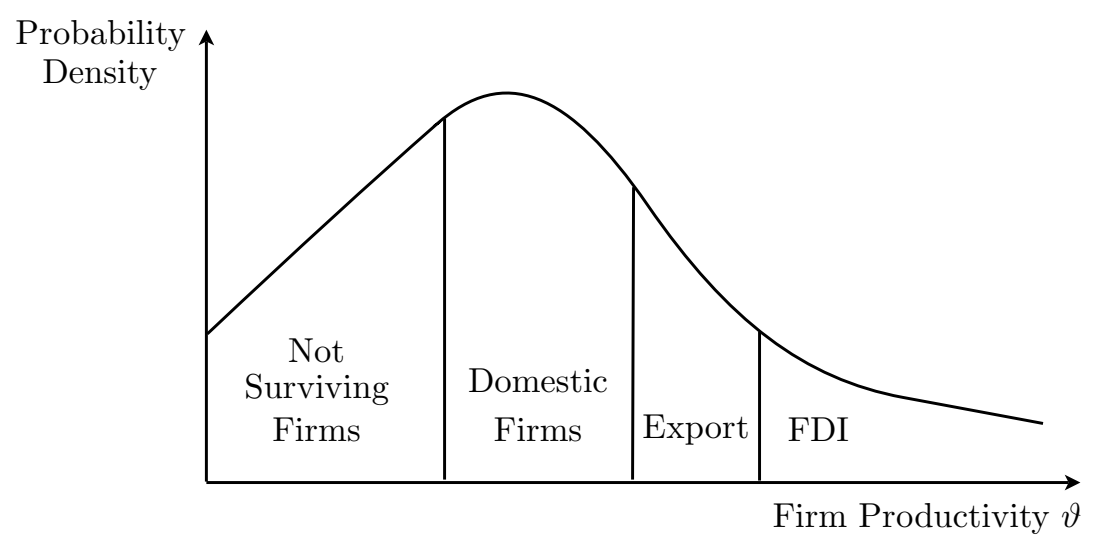

Figure 1: Firm distribution and productivity

distribution is a result of a lottery in which firms experience their final productivity level after paying the market entry costs. The model has been tested in various empirical works (Girma et al., 2005; Wagner, 2006), and its core predictions are well reflected in the data (Helpman, 2006). Helpman et al. (2004) e.g. analyze U.S. exports and affiliate data based on a Pareto distribution for ex ante uncertainty, covering 38 countries and 52 manufacturing sectors and are able to identify the significance of the relationship between productivity and the mode of serving a new foreign market. The New New Trade Theory emphasizes that the firm distribution within an industry is not a random sample. In steady-state, productivity turns out to be an appropriate variable to explain the selection effects within an industry. However, within this new workhorse theory it is difficult to derive transition predictions, especially on how the firms select their market entry mode. Helpman et al. (2004) introduce productivity uncertainty as a one-time shock effect which determines the final firm distribution.

On the other hand, from a microeconomic perspective, firms base their market entry decision on intertemporal profit maximization. Within this optimization calculus, productivity uncertainty is not considered as a one time exogenous phenomenon but as a continuous aspect.

Faggio et al. (2007) e.g. present empirical data about the development of total factor productivity (TFP) for different sectors and for the whole economy in the U.K., starting in 1984. The authors show that besides a steady growth of TFP in the last decade, furthermore productivity dispersion in different sectors has increased. Bloom et al. 2007 show additionally that firm productivity exhibits a steady but volatile growth over time.

Given these insights, decision makers posses at least an expectation about their intertemporal productivity development in their home and foreign country. Based on historical experiences or 
on market analysis they anticipate a specific development of prospective productivity and decide on an appropriate market entry mode. Indeed, in the long run the self-selection within a sector will be based on survival arguments which can be modeled by a static productivity uncertainty as in Helpman et al. (2004). Still, the question remains whether it is appropriate to neglect the continuous volatile motion of firm productivity, especially if first time market entry modes are modeled.

In contrast to trade models, modern finance theory analyzes investment behavior by combining continuous uncertainty with fixed costs in an intertemporal framework (McDonald and Siegel, 1986; Pindyck, 1991). This strand of literature is known as the real option approach and has been extended among others by Dixit and Pindyck (1994). Although the theoretical framework turns out to be relatively complex, the approach is increasingly used by decision makers to assess enterprise strategies, especially in investment related questions (Leslie and Michaels, 1997). To shed light on the question whether continuous productivity uncertainty has a different impact on the export and FDI decision of an investor, the real option approach represents therefore a promising and appropriate framework.

The following model combines the proximity-concentration trade-off framework with an uncertain productivity growth (Geometric Brownian motion) to analyze the first time foreign market entry strategy of an investor who can choose between export and FDI. In order to work out the specific differences between a static and dynamic theoretical framework the analysis is conducted in three progressive steps. Starting from a framework without productivity growth, conditions for the optimal market entry mode are derived. In a second step productivity is assumed to grow deterministically, which leads to a broader set of choices for the investor as he can postpone his investment decision. Finally, productivity growth is modeled as a stochastic process accounting for the most realistic scenario.

Results of the model support the New New Trade Theory findings, as continuous uncertainty provides implicitly the same market entry patterns. Confronted with continuous risk, a firm will enter a new foreign market through exports at lower productivity levels relative to the FDI mode. Additionally, the model allows a deeper understanding of the chosen market entry mode under continuous productivity uncertainty. 


\section{Theoretical Framework}

Several assumptions are introduced in order to elaborate essential effects of uncertain productivity growth on the choice of the optimal market entry mode. ${ }^{1}$

Consider a risk neutral investor who can serve a new foreign market with a specific product brand $X_{i}$ either through exports, produced in the home country or through a new foreign affiliate plant (horizontal FDI), located in the destination country. These two market entry modes represent investment strategies which are substituting channels to sell $X_{i}$ on the new market. The final decision on how to enter the foreign market is based on the comparison of the export investment value $V_{E}$ with the alternative FDI strategy value $V_{F}$. The investment horizon is assumed to be infinite and market entry can be postponed without any negative effects on revenues.

\subsection{Demand Side}

The destination country's utility function is assumed to be given by

$$
\begin{aligned}
& U_{t}\left(Q_{t}, Y_{t}\right)=Q_{t}^{\gamma} Y_{t}^{1-\gamma} \\
& \text { with } Q_{t}=\left(\sum_{i=1}^{n_{t}} X_{i_{t}}^{\rho}\right)^{\frac{1}{\rho}}, \quad 0<\rho<1, \quad 0<\gamma<1,
\end{aligned}
$$

where $Q_{t}$ represents a differentiated product with $n_{t}$ varieties. $X_{i_{t}}$ is the consumed amount of brand $i$ only produced by the considered investor. $\rho$ represents the degree of substitution between any two brands of $Q_{t}$. $Y_{t}$ is a homogeneous composite good, freely traded and therefore, used as numeraire good with a normalized fixed world market price, equal to unity. The foreign household maximizes utility subject to the budget constraint

$$
\sum_{i=1}^{n_{t}} X_{i_{t}} p_{i_{t}}+Y_{t} \leqq \xi_{t}
$$

where $\xi_{t}$ represents the foreign country's total expenditure and $p_{i_{t}}$ the price of variety $i$ in $t$. The

\footnotetext{
1 The term uncertainty will be used in an interchangeable manner with the term risk. In a concise way, risk refers to a known probability distribution whereas uncertainty is referring to events in which the numerical probabilities cannot be specified. In this paper I do not follow this distinction.
} 
demand function of variety $i$ is then derived as

$$
\begin{aligned}
& X_{i_{t}}=\frac{p_{i_{t}}^{-\eta}}{P_{t}^{-\eta}} \cdot \frac{\gamma \xi_{t}}{P_{t}} \\
& \text { with } \quad \eta=\frac{1}{1-\rho}, \quad P_{t}=\left(\sum_{j_{t}}^{n_{t}} p_{j_{t}}^{1-\eta}\right)^{\frac{1}{1-\eta}},
\end{aligned}
$$

where $P_{t}$ denotes the foreign country's price index and $\eta$ the elasticity substitution. The investor insinuates that the expenditure share $\gamma \xi$ spent on $Q$ and the price index $P$ do not change over time. Therefore, equation (3) represents the investor's perceived demand function and the inverse demand for the relevant variety $X_{i}$ can be written as

$$
\begin{aligned}
& p_{t}=Z X_{t}^{-\frac{1}{\eta}} \\
& \text { with } \quad Z=P^{\frac{\eta-1}{\eta}}(\gamma \xi)^{\frac{1}{\eta}},
\end{aligned}
$$

where the considered variety's subscript $i$ is omitted, as the investor intends to serve the foreign market only with this distinctive brand. Furthermore, there is no strategic interaction among firms. Depending on the country specific elasticity of substitution, the investor possesses a varying degree of market power. The mark-up of price over marginal costs

$$
\frac{p}{w}=Z\left(\frac{\eta}{\eta-1}\right)
$$

with $w$ as the equilibrium wage rate, results from the investor's profit maximization problem as a monopolist. Defining $\nu$ as the inverse of the mark-up with

$$
\nu=\frac{\eta-1}{\eta}
$$

the inverse demand function can be reformulated as

$$
p=Z X^{\nu-1}
$$

In a country, where $\nu$ is close to 0 , the elasticity of demand is close to 1 which represents a scenario where the investor has a high monopoly power, since the substitutability between the varieties of good $Q_{t}$ is very low $(\rho \rightarrow 0)$. In contrast, for a country with $\nu$ close to 1 , the elasticity 
of demand approaches infinity and the substitutability between the varieties of $Q_{t}$ is very high $(\rho \rightarrow 1)$. In such a country the investor is confronted with a perfectly competitive environment. As a result of this modified notation, $\nu$ can be used as a country specific competition measure for a variety $X$.

\subsection{Production Side}

In both, the home and foreign country, the investor is confronted with a production technology characterized by the Cobb-Douglas function

$$
\begin{aligned}
& X_{t}\left(L_{t}\right)=\vartheta_{t} L_{t}^{\theta} \\
& \text { with } 0<\theta<1 \text { and } \vartheta_{t}>0,
\end{aligned}
$$

where $X_{t}$ denotes the periodical output and labor $L_{t}$ the only input factor. $\vartheta_{t}$ represents a productivity parameter and is referred to as the firm embedded productivity, because it is specific to the idiosyncratic firm independently of its location. In both market entry strategies the investor is confronted with fixed costs which are assumed to be sunk once invested. If the foreign market is served through exports, fixed costs $I_{E}$ accrue. They include costs for the domestic production extension and expenses for a new foreign distribution and service network. In case of a FDI market entry mode fixed costs $I_{F}$ must be covered which include the same distribution and service network costs as the export mode. However, due to the required new plant in the FDI mode, its fixed costs are assumed to be always higher than the export fixed costs $I_{E} \cdot{ }^{2}$ Given these irreversible fixed costs, both investment strategies exhibit increasing returns to scale.

Additionally, exports are subject to iceberg transport costs described by the transport technology

$$
\lambda(\tau)=\tau-1 \quad \text { with } \quad \tau>1 .
$$

The extra domestic output $X_{D E_{t}}$, which is produced only for the new foreign market, shrinks during the transportation process by the constant factor $(\tau-1)$. The residual output $X_{E_{t}}$ which

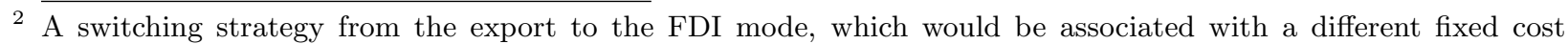
structure, is assumed to be not possible. In a dynamic framework such an extension necessitates numerical methods (Dixit and Pindyck, 1994). 
is finally sold in the destination country results as

$$
X_{E_{t}}=\frac{X_{D E_{t}}}{\tau}
$$

Transport costs are avoided if the investor decides to serve the foreign market through a new affiliate. The wage rate $w$ is determined in the homogeneous good industry $Y$, where the foreign country exhibits a lower wage rate than the investor's home country due to a less efficient production technology. The resulting fixed and variable cost structure with

$$
\frac{I_{E}}{I_{F}}<1 \text { and } \frac{w_{F}}{w_{E} \tau^{\frac{1}{\theta}}}<1
$$

is the proximity-concentration trade-off assumption, which is fundamental in recent trade models dealing with international market entry strategies and represents the first crucial pillar in the underlying model (Brainard, 1997, Helpman et al., 2004, and Yeaple, 2008).

\subsection{The Evolution of Productivity}

The major objective within the established theoretical framework is the analysis of firm-embedded productivity, introduced as $\vartheta_{t}$, and its impact on the optimal market entry mode under different scenarios. Therefore, a more accurate coverage of possible productivity developments is necessary. From a theoretical point of view productivity can evolve in three different manners over time.

1. $\vartheta$ stays constant over time (no productivity growth).

2. $\vartheta$ constantly increases over time (deterministic productivity growth).

3. $\vartheta$ exhibits a volatile productivity increase over time (stochastic productivity growth).

Analytically, these productivity evolutions can be easily modeled by using the following Geometric Brownian motion denoted in differential notation as

$$
d \vartheta_{t}=\alpha \vartheta_{t} d t+\sigma \vartheta_{t} d z_{t}
$$

where the parameters $\alpha$ and $\sigma$ are assumed to be time invariant and represent the growth rate and extent of volatility, respectively. $d z_{t}$ is the increment of a standard Brownian motion $z_{t}$ with

$$
d z_{t}=\epsilon_{t} \sqrt{d t} \quad \text { and } \quad \epsilon_{t} \sim N(0,1)
$$


where $\epsilon_{t}$ is assumed to be a Gaussian random variable. Therefore, the expected value and the variance of the standard Wiener process' increment result as $\mathbb{E}\left(d z_{t}\right)=0$ and $\mathbb{V}\left(d z_{t}\right)=d t$.

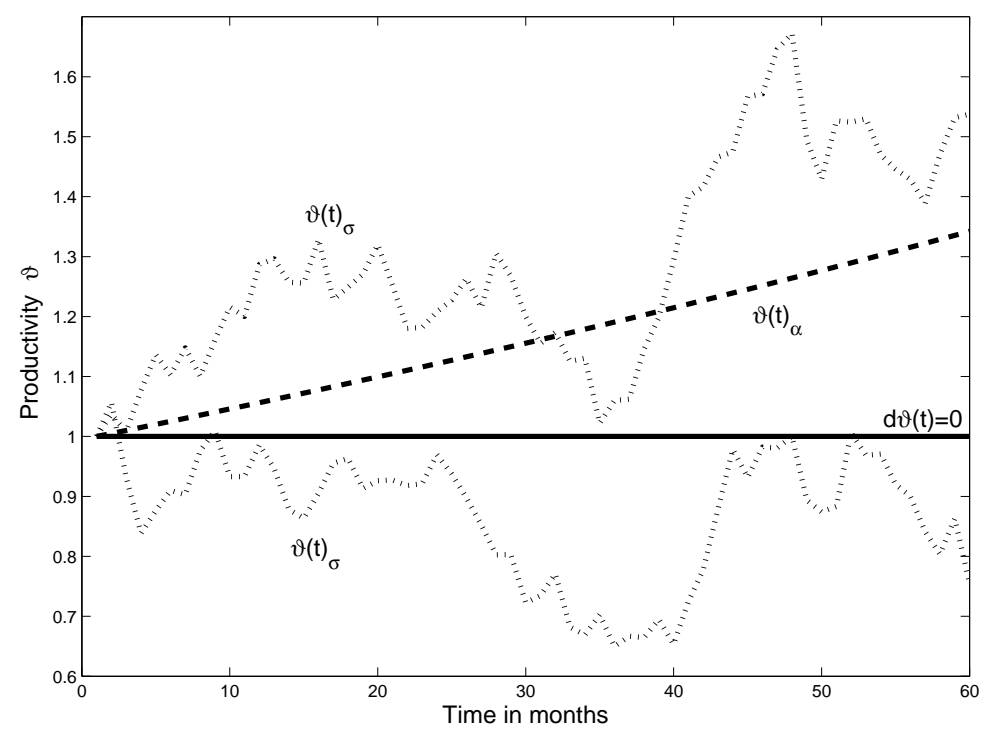

Figure 2: Exemplary Productivity Paths

Figure 2 illustratively depicts the realizations of the above mentioned productivity paths. The increasing dashed line exhibits a yearly growth rate of $6 \%$ and no volatility as $\mathbb{E}\left(d z_{t}\right)=0$. In such a case after 5 years, productivity can be expected to be $33 \%$ higher than initially. For a volatile productivity growth with $\sigma>0$, it is no longer possible to predict a unique path. The dotted trajectories represent 2 potential developments for a scenario with $\sigma=4 \%$ out of infinite possibilities. The simplest case is depicted by the horizontal curve which represents a scenario without growth. ${ }^{3}$

Due to its coverage of all possible productivity developments, the Geometric Brownian motion in equation (11) represents the second pillar in this model. By combining the established proximityconcentration trade-off framework with the Geometric Brownian motion in productivity, the succeeding analysis examines the optimal first time market entry strategy of an international investor in all these scenarios separately.

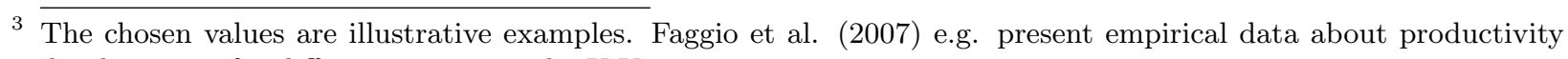
developments for different sectors in the U.K. 


\section{The Optimal Market Entry Mode}

In order to elaborate uncertainty effects of productivity growth on the choice between FDI and export, the analysis starts with the simplest scenario with no productivity changes over time. Successively, the complexity of the analysis is increased by introducing a deterministic growth case and finally by considering the most realistic scenario represented by equation (11). This stepwise approach permits an identification of the additional effects associated with extensions.

\subsection{FDI or Export without Productivity Growth}

In a scenario without any productivity growth equation (11) reduces to $d \vartheta_{t}=0$ and the investor will determine the optimal market entry mode based on the current state of observations, as there are no expected productivity changes in the future. Empirically, it is difficult to identify such an industry or variety in the long run but in some sectors like in the textile industry, technology has reached its marginal productivity frontier temporarily, and one can assume nearly zero growth rates, at least in the short run. From a theoretical point of view, this scenario only represents a starting point for further analysis.

In the export mode the investor's expected periodical profits (cash-flows) $\Pi_{E}$ are derived from the following maximization problem

$$
\Pi_{E}=\max _{L} p X_{E}-w_{E} L \quad \text { s.t. } \quad X_{E}=\frac{X_{D E}}{\tau} \quad \text { s.t. } \quad X_{D E}=\vartheta L^{\theta} \quad \text { s.t. } \quad p=Z X_{E}^{(\nu-1)} .
$$

Optimal periodical labor demand $L_{E}^{*}$ and output $X_{E}^{*}$ result as

$$
L_{E}^{*}=\left(\frac{\vartheta^{\nu} Z \nu \theta}{w_{E} \tau^{\nu}}\right)^{\frac{1}{1-\nu \theta}} \quad \text { and } \quad X_{E}^{*}=\vartheta^{\frac{1}{1-\nu \theta}}\left(\frac{Z \nu \theta}{w_{E} \tau^{\frac{1}{\theta}}}\right)^{\frac{\theta}{1-\nu \theta}}
$$

where the investor's domestic output which is foreseen for the export market amounts to

$$
X_{D E}^{*}=\vartheta^{\frac{1}{1-\nu \theta}}\left(\frac{Z \nu \theta}{w_{E} \tau^{\nu}}\right)^{\frac{\theta}{1-\nu \theta}}
$$


Finally, the optimal expected periodical export cash-flows are given as

$$
\begin{aligned}
& \Pi_{E}(\vartheta)=M_{E} \vartheta_{E}^{\kappa} \\
& \text { with } \quad M_{E}=Z^{\frac{1}{1-\nu \theta}}\left(\frac{\nu \theta}{w_{E} \tau^{\frac{1}{\theta}}}\right)^{\frac{\nu \theta}{1-\nu \theta}}(1-\nu \theta) \quad \text { and } \quad \kappa=\frac{\nu}{1-\nu \theta} .
\end{aligned}
$$

Transport costs do not accrue in the FDI mode $(\tau=1)$ and expected periodical profits result as ${ }^{4}$

$$
\begin{aligned}
& \Pi_{F}(\vartheta)=M_{F} \vartheta^{\kappa} \\
& \text { with } \quad M_{F}=Z^{\frac{1}{1-\nu \theta}}\left(\frac{\nu \theta}{w_{F}}\right)^{\frac{\nu \theta}{1-\nu \theta}}(1-\nu \theta) \quad \text { and } \quad \kappa=\frac{\nu}{1-\nu \theta} .
\end{aligned}
$$

Cash-flows in both entry modes can be linear, convex, or concave in $\vartheta$ depending on $\kappa$. The following analysis focuses on cases in which the cash-flows are linear or convex in $\vartheta$ since this is a common assumption in recent trade models (Helpman, 2006). ${ }^{5}$

In order to choose the optimal market entry mode, the investor compares both market entry strategies' net present investment values which are associated with the earlier explained fixed costs. The opportunity costs in this certain scenario are equal to the riskless interest rate $r$ and therefore, net present values of the export and FDI mode result as

$$
\begin{gathered}
V_{E}(\vartheta)-I_{E}=\frac{M_{E} \vartheta^{\kappa}}{r}-I_{E} \\
V_{F}(\vartheta)-I_{F}=\frac{M_{F} \vartheta^{\kappa}}{r}-I_{F} .
\end{gathered}
$$

Figure 3 depicts the export strategy's investment value as a continuous line and the FDI mode's value as a dotted line. ${ }^{6}$ The two curves' relative position to each other is not random but enforced by the proximity-concentration trade-off assumption. As the fixed costs in the export mode are assumed to be lower than in the FDI mode (comparative fixed cost advantage), for $\vartheta=0$ the net investment value $V_{E}-I_{E}$ will always be higher than $V_{F}-I_{F}$. Furthermore, due to the higher variable costs in the export mode a gain in productivity leads to a higher marginal increase in the FDI investment value (comparative variable cost advantage). Differently expressed, the slope of

\footnotetext{
4 The optimal labor demand and output in the FDI mode are $L_{F}^{*}\left(\frac{Z \vartheta^{\nu} \nu \theta}{w_{F}}\right)^{\frac{1}{1-\nu \theta}}$ and $\quad X_{F}^{*}=\left(\frac{Z \nu \theta \vartheta^{\frac{1}{\theta}}}{w_{F}}\right)^{\frac{\theta}{1-\nu \theta}}$.

${ }^{5}$ Cash-flows will be always linear or convex in $\vartheta$ for $\kappa \geq 1$.

${ }^{6}$ The domestic investment value $V_{D}$ of the plant which serves the investor's home market is neglected. Implicitly, it is assumed that $V_{D}$ is not affected by the new foreign market entry.
} 
$V_{F}-I_{F}$ will always be steeper than the slope of $V_{E}-I_{E}$. As a result, the export value function crosses the FDI value function always from above as depict in figure 3. In the underlying example,

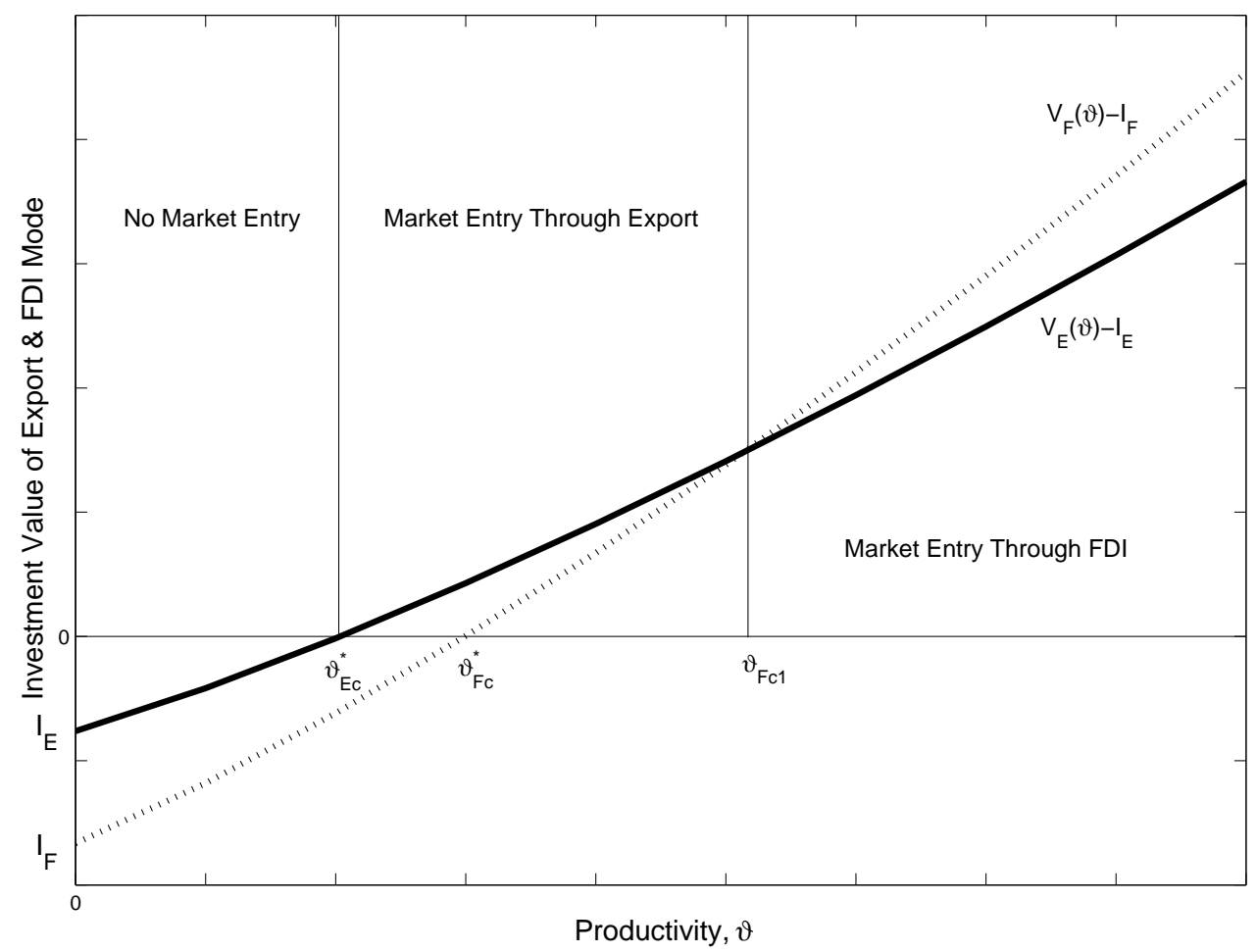

Figure 3: Investment Values within the Proximity-Concentration Trade-Off

an investor will serve the new foreign market through FDI if the prevailing productivity level is larger than $\vartheta_{F c 1}$ and for a productivity level between $\vartheta_{E c}$ and $\vartheta_{F c}$ exporting turns out to be the optimal market entry strategy. For the remaining productivity range, market entry implies losses in both modes and is therefore discarded.

A decisive aspect whether the FDI strategy dominates the export mode or vice versa depends on the rank of the productivity cut-offs which result from equation (18) and (19) as

$$
\vartheta_{E c}^{*}=\sqrt[\kappa]{\frac{I_{E} r}{M_{E}}} \quad \text { and } \quad \vartheta_{F c}^{*}=\sqrt[\kappa]{\frac{I_{F} r}{M_{F}}}
$$

Figure 3 illustratively depicts a case in which the intersection between the two value functions takes place above the horizontal-axes. However, for a cost structure with export fixed costs $I_{E}$ close to FDI fixed costs, the two value functions may intersect on or below the horizontal axes. In such a case, only the FDI strategy provides relevant zero or positive net present values and it would represent the upper envelope function in figure 3. Simultaneously, its cut-off productivity 
level $\vartheta_{F c}^{*}$ will be always equal to or below $\vartheta_{E c}^{*}$. Consequently, for such cost constellations FDI represents the only and optimal market entry strategy conditional on positive net present values. It is possible to derive a concise condition which describes the ordinal rank between the two productivity cut-offs. It can be shown that

$$
\frac{\vartheta_{E c}^{*}}{\vartheta_{F c}^{*}} \lesseqgtr 1 \quad \text { if } \quad \frac{I_{E}}{I_{F}} \lesseqgtr\left(\frac{w_{F}}{w_{E} \tau^{\frac{1}{\theta}}}\right)^{\frac{\nu \theta}{1-\nu \theta}}
$$

Within the assumed relative cost structure, relation (21) states that the export mode's productivity cut-off $\vartheta_{E c}^{*}$ is smaller (equal, bigger) than the FDI productivity cut-off $\vartheta_{F c}^{*}$ if its fixed cost advantage is bigger (equal, smaller) than the FDI mode's variable cost advantage. Since within

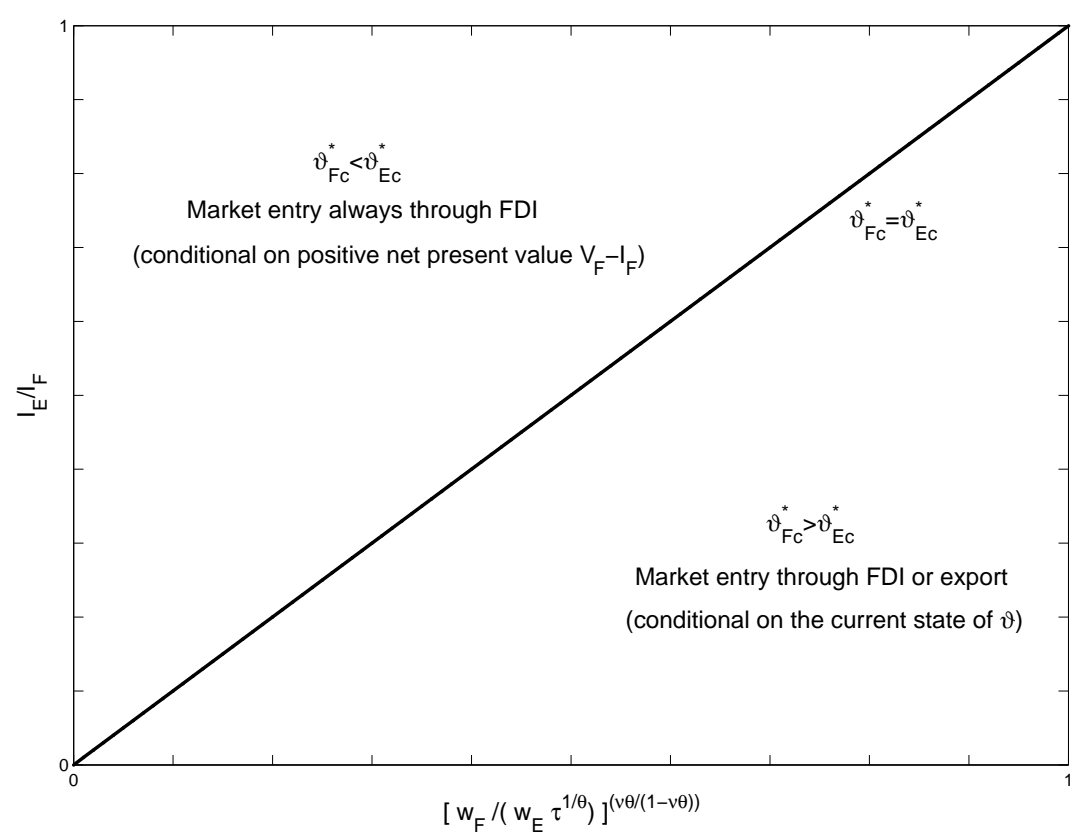

Figure 4: Relative Cost Constellations within the Proximity-Concentration Trade-Off

the proximity-concentration trade-off framework relative fixed costs $\frac{I_{E}}{I_{F}}$ and relative variable costs $\left(\frac{w_{F}}{w_{E} \tau^{\frac{1}{\theta}}}\right)^{\frac{\nu \theta}{1-\nu \theta}}$ never exceed unity, it is possible to depict all relevant cost patterns in a unit relative cost box. The diagonal curve in Figure 4 represents all relative cost constellations for the FDI and export mode which exhibit a comparative fixed cost advantage equal to the comparative variable cost advantage, given the technology concavity $\theta$ and the country specific degree of competition $\nu$. Therefore, any relative cost structure on or above the diagonal line leads to a FDI productivity cut-off $\vartheta_{F c}^{*}$ being equal to or bigger than $\vartheta_{E c}^{*}$. In both cases the FDI mode's 
net present value function would represent the upper envelope in figure 3 and the investor serves the market through a foreign plant, conditional on a positive net present value. Any relative cost constellation below the diagonal curve in figure 4 leads to a cut-off rank with $\vartheta_{E c}^{*}$ always lower than $\vartheta_{F c}^{*}$ which would be represented by an upper envelope function in figure 3 consisting of both, the FDI and export mode's net present value functions. Therefore, in such a case the optimal market entry strategy depends on the current observed productivity state $\vartheta$ and can be either FDI or exporting. The investor will choose the export mode if the observed current productivity level $\vartheta$ lies in-between the two productivity cut-offs $\vartheta_{E c}^{*}, \vartheta_{F c 1}$ and fulfills the following condition

$$
\vartheta_{F c 1}>\vartheta>\sqrt[\kappa]{\left(\frac{I_{E}-I_{F}}{M_{E}-M_{F}}\right) r}>\vartheta_{E c}^{*} .
$$

An essential result in the underlying scenario with no growth and no uncertainty is that $50 \%$ of all possible relative cost structures (upper left corner in figure 4) unambiguously entail FDI as the optimal market entry strategy, conditional on positive net present values. Furthermore, the export mode never becomes a unique dominant strategy as the lower left corner in figure 4 can lead to both export and FDI.

\section{Result 1:}

Given $I_{E}<I_{F}$ and $w_{F}<w_{E} \tau^{\frac{1}{\theta}}$, for more than $50 \%$ of all possible relative cost constellations within the proximity-concentration trade-off framework, FDI represents the unique optimal market entry mode.

The upper horizontal margin in figure 4 typifies relative cost constellation for which the fixed costs in both market entry modes are equal, but the variable costs are always lower in the FDI mode. Therefore, the investor will always opt for FDI. Analogously, for all cost constellations positioned on the right vertical margin in figure 4 both market entry modes exhibit equal total variable costs. Due to the lower fixed costs in the export strategy, in such cases the investor will always enter the market as exporter. Finally, the upper right corner in figure 4 represents a cost constellation for which the fixed cost advantage of the FDI mode is equal to the variable cost advantage of the export mode and therefore, the investor is indifferent between the two market entry strategies. 


\subsection{FDI or Export with Productivity Growth}

A more realistic scenario for productivity development can be modeled as

$$
d \vartheta_{t}=\alpha \vartheta_{t} d t
$$

with $\alpha$ representing the productivity growth rate. Given the initial exponential cash-flows in equation (16) and (17) it is necessary to adjust the growth rate for cases in which $\kappa>1$. The adjusted growth rate for convex profit flows results as

$$
\alpha^{\prime}=\frac{d \vartheta^{\kappa}}{\vartheta^{\kappa}}=\alpha \kappa
$$

Still, without any risk, the appropriate discount rate is equal to the riskless interest rate $r$. Consequently, for both strategies the gross value of their periodical cash-flows is determined by

$$
\begin{aligned}
& V_{i}(t, T)=\int_{t+(T-t)}^{\infty} M_{i} \vartheta^{\kappa}(s) e^{-r(s-t)} d s \\
& \text { with } \vartheta^{\kappa}(s)=\vartheta_{t}^{\kappa} e^{\alpha^{\prime} s} \text { and } i \in\{E, F\} .
\end{aligned}
$$

$T$ represents the time at which periodical profits start to flow and $t$ the time at which the cashflows are evaluated, with $\vartheta_{0}$ representing the current productivity state. Therefore, the gross present value of growing periodical cash-flows $(t=0)$ is given by $^{7}$

$$
V_{i}(0, T)=\frac{M_{i} \vartheta_{0}^{\kappa}}{\delta_{c}^{\prime}} e^{-\left(r-\alpha^{\prime}\right) T} \quad \text { with } \quad \delta_{c}^{\prime}=r-\alpha^{\prime}
$$

In contrast to the previous scenario an investor is not only confronted with the choice problem between exporting and FDI. Additionally, a timing problem arises where the following net pay-offs $F_{i}(\vartheta)$ are optimized.

$$
F_{i}(\vartheta)=\max _{T}\left(\frac{M_{i} \vartheta^{\kappa}}{r-\alpha^{\prime}} e^{-\left(r-\alpha^{\prime}\right) T}-I_{i} e^{-r T}\right), \quad \text { with } \quad \vartheta=\vartheta_{0}, \quad i \in\{E, F\}
$$

Equation (28) clearly illustrates the unequal total discount rates of the cash-flows and the fixed costs. For $\alpha=0$ which represent the previous scenario, there is no reason to postpone or delay

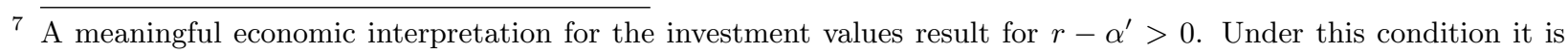
necessary that $\beta_{c}>\kappa>1$ with $\beta_{c}=\frac{r}{\alpha}$.
} 
an investment. The investment takes place if the discounted profit flows are equal or bigger than the discounted fixed costs in $t$ (Marshallian rule). The corresponding investment rule results as

$$
F_{i}(\vartheta)=\max \left[V_{i}(0, T)-I_{i}, 0\right]
$$

On the other hand for a growth rate $\alpha>0$ the investor has an incentive to postpone the project in order to maximize his pay-off, although the current gross value of the cash-flow streams may be bigger than the current fixed costs. Solving the maximization problem in (28) provides the optimal investment times for both market entry modes:

$$
T_{i}^{*}=\max \left(\frac{1}{\alpha^{\prime}} \ln \left[\frac{r I_{i}}{M_{i} \vartheta^{\kappa}}\right], 0\right) \quad \text { with } \quad i \in\{E, F\}
$$

For periodical profit flows not too much larger than the user cost of capital $r I_{i}$, both investment strategies will be postponed into the future since $T_{i}^{*}>0$. Due to the proximity-concentration trade-off assumption the optimal market entry time of exporting clearly differs from the optimal market entry time of the FDI strategy. For the sake of a better comparability between the different scenarios it is useful to determine the optimal productivity cut-offs $\vartheta_{i}^{*}$ in both investment strategies. By setting the optimal investment time $T_{i}^{*}$ equal to zero it is possible to derive the investment rule and the optimal cut-off productivity $\vartheta_{i}^{*}$ which triggers market entry at $t=0$, respectively. An instantaneous investment in both modes results if

$$
r I_{i}=\left(r-\alpha^{\prime}\right) \frac{M_{i} \vartheta^{\kappa}}{\left(r-\alpha^{\prime}\right)}=M_{i} \vartheta^{\kappa} \quad \text { with } \quad i \in\{E, F\}
$$

which states that the investor will execute one of the two investment alternatives if the corresponding cash-flows $M_{i} \vartheta^{\kappa}$ cover their cost of capital use $r I_{i}$. This optimality condition is known as the Jorgensonian investment rule (Jorgenson, 1963) and slightly differs from the generally applied Marshallian rule, which compares the absolute fixed costs with the gross investment values. By contrast Jorgenson's rule represents a marginal concept and in the presence of productivity growth, it leads to an investment rule where fixed costs need not only to be covered by the gross present value $V_{i}(\vartheta)$ but by relatively higher values. 
Reshaping equation (31) provides

$$
V_{i}(\vartheta)=\frac{M_{i} \vartheta^{\kappa}}{\left(r-\alpha^{\prime}\right)}=\left(\frac{r}{r-\alpha^{\prime}}\right) I_{i} \quad \text { with } \quad \frac{r}{r-\alpha^{\prime}}>1
$$

where the wedge in front of the fixed costs is bigger than one, if $\alpha>0$. Therefore, in absence of productivity growth (earlier scenario) the derived condition coincides with the Marshallian investment rule and no timing problem occurs. On the other hand, for positive productivity growth rates the investor will postpone his market entry decision (export or FDI) into the future $T_{i}^{*}$ although the net payoffs are positive.

For a market entry in $T_{i}^{*}$ the net present values of both investment modes result as

$$
F_{i}(\vartheta)=\frac{\alpha^{\prime} I_{i}}{r-\alpha^{\prime}}\left(\frac{r-\alpha^{\prime}}{r}\right)^{\frac{r}{\alpha^{\prime}}}\left(\frac{M_{i} \vartheta^{\kappa}}{r-\alpha^{\prime}}\right)^{\frac{r}{\alpha^{\prime}}} I_{i}^{-\frac{r}{\alpha^{\prime}}}
$$

and are referred to as the option values. Clearly, for $\alpha=0$ these value functions become worthless. Given the two possible investment times $\left(t_{i}=0, T_{i}^{*}\right)$ for each market entry strategy the investor will compare the net investment value $V_{i}(\vartheta)-I_{i}$ with its corresponding option value $F_{i}(\vartheta)$. By defining

$$
A_{i_{c}}=\frac{\alpha^{\prime} I_{i}}{r-\alpha^{\prime}}\left(\frac{r-\alpha^{\prime}}{r}\right)^{\frac{r}{\alpha^{\prime}}}\left(\frac{M_{i}}{r-\alpha^{\prime}}\right)^{\frac{r}{\alpha^{\prime}}} I_{i}^{-\frac{r}{\alpha^{\prime}}} \text { and } \quad \beta_{c}=\frac{r}{\alpha}
$$

the two value functions which determine each market entry mode's optimal timing, result as

$$
\begin{array}{llll}
F_{i}(\vartheta)=A_{i_{c}} \vartheta^{\beta_{c}} & \text { for } & \vartheta_{i}<\vartheta_{i}^{*} & \text { postpone investment to } T_{i}^{*} \\
V_{i}(\vartheta)-I_{i} & \text { for } & \vartheta_{i}>\vartheta_{i}^{*} & \text { invest today }(t=0) \\
\text { with } \quad i \in\{E, F\}, & & &
\end{array}
$$

where the cut-off productivity levels are represented by $\vartheta_{i}^{*}$.

The existence of productivity growth $(\alpha>0)$ has two new effects on the market entry choice of the investor. Equation (27) demonstrates that the gross present value of both investments increases in $\alpha$. In comparison to the previous scenario, the investor is confronted with lower productivity cutoffs as the net present value functions increase. However, simultaneously growth in productivity generates an option value represented by (33) which eliminates this effect completely, as the 
investments are postponed. A graphical illustration visualizes the different adjustments very clearly. The two continuous curves in figure 5 represent the net present investment values for

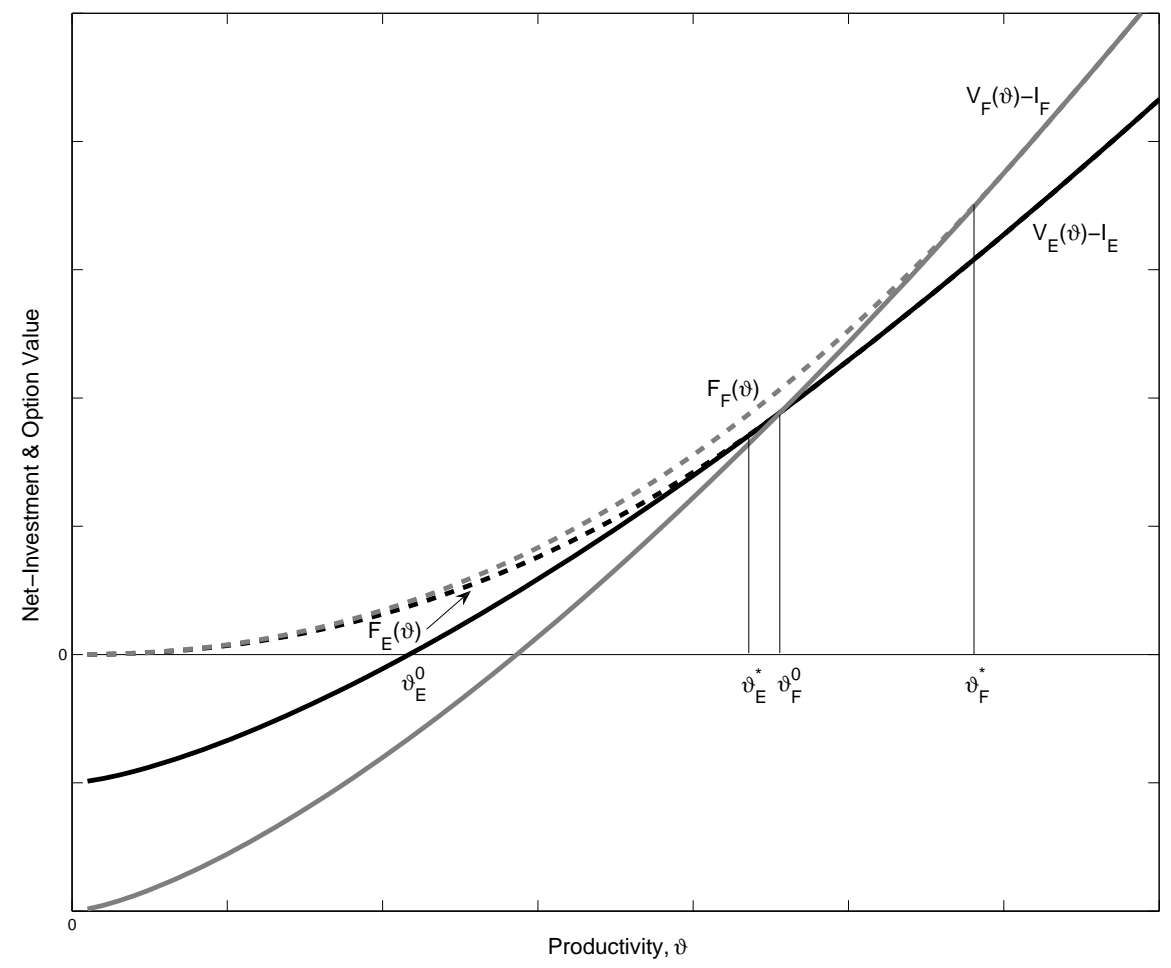

Figure 5: Value Functions of Exporting and FDI

both market entry strategies in the presence of productivity growth, whereas the dashed lines represent the corresponding option values. If the investor decides on the market entry problem by applying the Marshallian rule, the optimal investment strategy is derived in the same manner as in a scenario without growth. In such a case for current productivity levels higher than $\vartheta_{F}^{0}$, FDI represents the optimal mode. Exporting is chosen for current productivity levels between $\vartheta_{E}^{0}$ and $\vartheta_{F}^{0}$. These cut-offs are all lower than those in scenario one as explained and would cause an earlier market entry in both strategies. However, for the determination of the optimal productivity cut-offs the investor additionally accounts for the option values as there is a timing problem. In contrast to scenario one, these optimal cut-offs result at the tangency point between the net present investment value function and the respective option value. At these points for each market entry mode, the net investment value equals its option value, respectively, and the investor does no longer postpone his investment decision. Rearranging the earlier derived Jorgensonian 
investment rule provides the productivity cut-offs for both market entry modes as

$$
\vartheta_{E}^{*}=\sqrt[\kappa]{\frac{\beta_{c}}{\beta_{c}-\kappa} \frac{I_{E} \delta_{c}^{\prime}}{M_{E}}} \quad \text { and } \quad \vartheta_{F}^{*}=\sqrt[\kappa]{\frac{\beta_{c}}{\beta_{c}-\kappa} \frac{I_{F} \delta_{c}^{\prime}}{M_{F}}} \quad \text { with } \quad \delta_{c}^{\prime}=r-\alpha^{\prime}
$$

The difference between the interest rate $r$ and the productivity growth rate $\alpha^{\prime}$ represents the real opportunity cost rate $\delta_{c}$. For a low productivity growth rate the opportunity costs of delaying each investment are high, whereas a high growth rate affects $\delta_{c}^{\prime}$ negatively.

In the illustrative example in figure 5 exporting is in principle profitable for a current productivity level between $\vartheta_{E}^{0}$ and $\vartheta_{E}^{*}$ if it is started instantaneously $(\mathrm{t}=0)$ but by starting in $T_{E}^{*}$ the net present profits represented by the option value $F_{E}(\vartheta)$ are higher. Therefore, exporting is postponed until the current productivity level reaches $\vartheta_{E}^{*}$ at which the investor is indifferent between postponing and investing into the export platform. Consequently, as long as there is a positive difference between the option value $F_{i}(\vartheta)$ and the net present value $V_{i}(\vartheta)-I_{i}$ there exists a value of waiting and the market entry is postponed into $T_{i}^{*}$. Due to the same reasoning, for productivity levels between $\vartheta_{F}^{0}$ and $\vartheta_{F}^{*}$, the investor postpones his FDI investment decision into $T_{F}^{*}$, although an immediate market entry would provide profits. Graphically expressed, it is the upper envelope function in figure 5 which determines the final optimal market entry mode.

Generally, the determination of the optimal market entry mode necessitates the consideration of two aspects. First, the investor needs again to determine the ordinal rank between the two productivity cut-offs.

It can be shown that the cut-offs' rank depends on the different cost structures with

$$
\frac{\vartheta_{E}^{*}}{\vartheta_{F}^{*}} \lesseqgtr 1 \quad \text { if } \quad \frac{I_{E}}{I_{F}} \lesseqgtr\left(\frac{w_{F}}{w_{E} \tau^{\frac{1}{\theta}}}\right)^{\frac{\nu \theta}{1-\nu \theta}}
$$

which is the same result as in scenario one.

The conclusion from this equivalent results is that the introduction of growth into the proximityconcentration trade-off framework does not change the relationship between the productivity cut-offs compared to the previous scenario. Figure 6 depicts the earlier introduced relative unit cost box within the proximity-concentration trade-off framework. The rank of the productivity cut-offs for all possible relative cost constellations is the same as in figure 4 .

In order to derive the optimal market entry strategy, it is necessary to determine how the two 
investment modes' option values behave for different cost-constellations. It can be shown that

$$
\begin{aligned}
& \frac{F_{E}}{F_{F}} \lesseqgtr 1 \text { if }\left(\frac{w_{F}}{w_{E} \tau^{\frac{1}{\theta}}}\right)^{\frac{\nu \theta}{1-\nu \theta}} \gtreqless \frac{I_{E}}{I_{F}}\left(\frac{I_{E}}{I_{F}}\right)^{-\frac{\kappa}{\beta_{c}}} \\
& \text { with } \quad \beta_{c}=\frac{r}{\alpha} .
\end{aligned}
$$

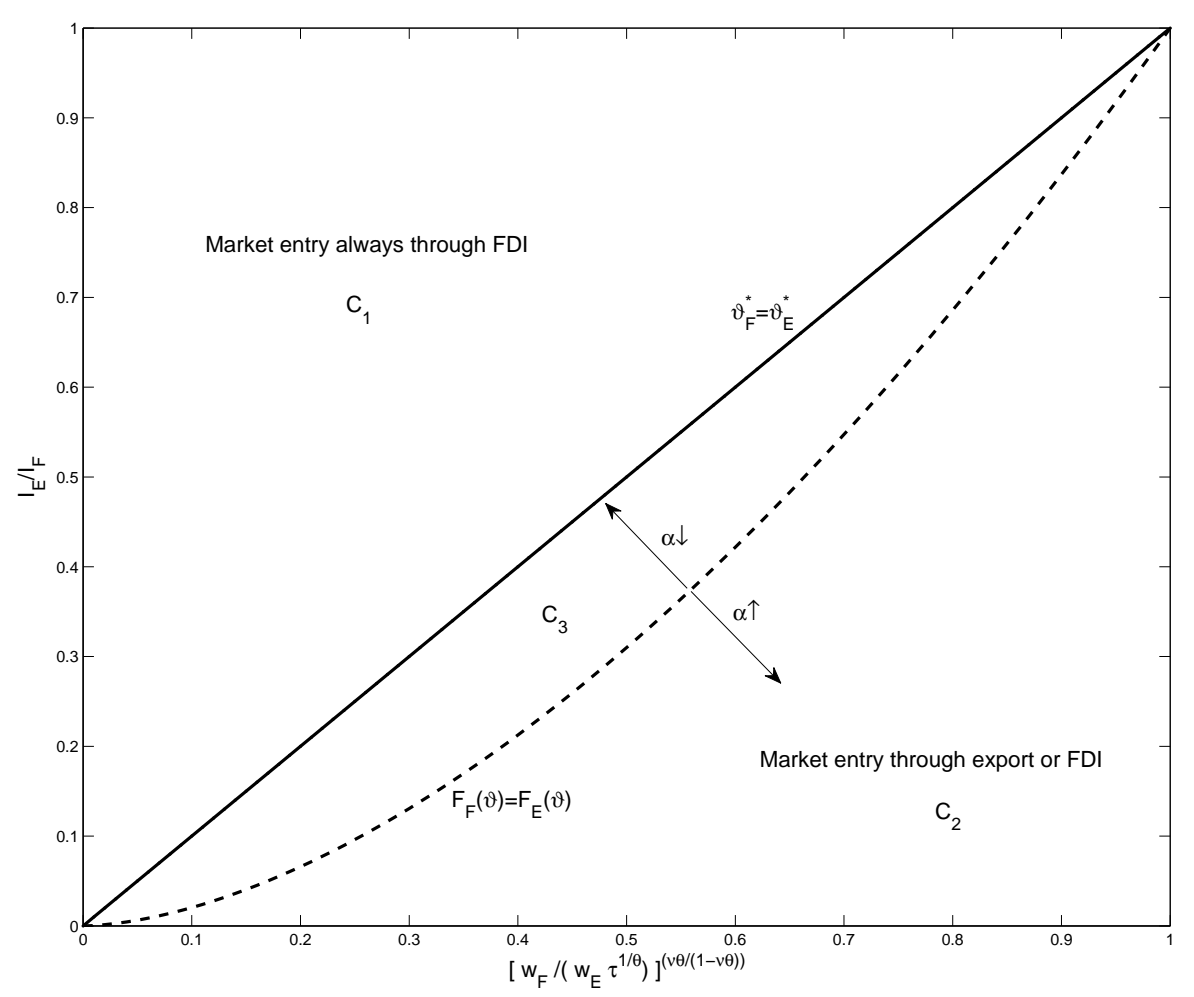

Figure 6: Relative Cost Constellations and Productivity Growth

Relation (38) is almost equal to the first condition in relation (37) except the second term on the right hand side which depends on the growth rate $\alpha$. Therefore, it can be drawn as dashed line in the previous relative unit cost box. Within the proximity-concentration trade-off framework, for all relative cost constellations on the dash line, the two market entry strategies' option functions coincide. Respectively, any cost structure above the line will exhibit a FDI option value $F_{F}(\vartheta)$ which is always bigger than the export option value $F_{E}(\vartheta)$. The opposite holds for cost constellations below the dashed line. Based on the two conditions (37) and (38) it is possible to derive the optimal market entry modes for different cost constellations presented in figure 6 . 
Relative Cost Structures in Area $C_{1}$ :

All relative cost patterns above the diagonal line, declared as area $C_{1}$, will lead to a FDI productivity cut-off $\vartheta_{F}^{*}$ which is always smaller than the export cut-off $\vartheta_{E}^{*}$. Simultaneously, the FDI mode's option function will always be higher than the export mode's one with

$$
F_{F}(\vartheta)>F_{E}(\vartheta) \text { and } \vartheta_{F}^{*}<\vartheta_{E}^{*}
$$

Therefore, in figure 5 the upper envelope function is always represented either through the FDI's option or net present value function. Consequently, for all these cost constellations an investor will unambiguously serve the foreign market through FDI, conditional on market entry.

\section{$\underline{\text { Relative Cost Structures in Area } C_{2}}$ :}

For cost constellations in area $C_{2}$ the relation between the two option functions and productivity cut-offs is given by

$$
F_{F}(\vartheta)<F_{E}(\vartheta) \text { and } \vartheta_{F}^{*}>\vartheta_{E}^{*}
$$

For these cost patterns figure 5 would map an upper envelope function consisting of all four available value functions. Depending on the current state of the productivity level the investor enters the market either through exports or FDI. Therefore, area $C_{2}$ does not lead to an unambiguous market entry strategy.

$\underline{\text { Relative Cost Structures in Area } C_{3}}$ :

Relative cost structures between the diagonal line and above the dash line are declared as area $C_{3}$ and lead to a formation of the option value functions and productivity cut-offs with

$$
F_{F}(\vartheta)>F_{E}(\vartheta) \text { and } \vartheta_{F}^{*}<\vartheta_{E}^{*}
$$

For these constellations the investor is in principle willed to enter the new foreign market through exports at lower productivity levels relative to the FDI mode. However, as the option value of the FDI mode is always higher than the two export value functions, exporting is always neglected for the sake of FDI. Figure 5 illustratively represents such a cost constellation and it can be shown 
that area $C_{3}$ will always lead to a market entry through FDI, since

$$
\begin{aligned}
& \left.\frac{F_{F}(\vartheta)}{V_{E}(\vartheta)}\right|_{\vartheta>\vartheta_{E}^{*}}>1 \\
& \left(\frac{w_{F}}{w_{E} \tau^{\frac{1}{\theta}}}\right)^{\frac{\nu \theta}{1-\nu \theta}}>\frac{I_{E}}{I_{F}}\left(\frac{I_{E}}{I_{F}}\right)^{\left(-\frac{\kappa}{\beta_{c}}\right)} .
\end{aligned}
$$

Area $C_{3}$ evolves for positive growth rates and its extent depends on the size of $\alpha$. Condition (38) shows for a decreasing $\alpha$ the exponent $\frac{\kappa}{\beta_{c}}$ approaches zero. Consequently, area $C_{3}$ diminishes until the dashed line in figure 5 coincides with the diagonal curve. This result represents the relative unit cost box for scenario one with $\alpha=0$ and confirms the consistency of the framework. On the contrary, an increase in $\alpha$ enlarges area $C_{3}$ as the dashed curve in figure 5 becomes more convex. The economic intuition for this adjustments follows from condition (38). An increase in productivity growth reduces the comparative fixed cost advantage of the export mode and implicitly increases the comparative variable cost advantage of the FDI strategy. Differently expressed, a rise in $\alpha$ increases the FDI mode's option value stronger than the export option value. Consequently, as area $C_{1}$ and $C_{3}$ unambiguously enforce market entry through FDI it can be concluded that within the proximity-concentration trade-off framework a rise in $\alpha$ increases the range of cost patterns which result in FDI.

\section{Result 2:}

For $I_{E}<I_{F}$ and $w_{E} \tau^{\frac{1}{\theta}}>w_{F}$ the availability of productivity growth increases the range of relative cost constellation which enforce FDI as the optimal market entry strategy. The higher the growth rate $\alpha$ the larger the share of cost patterns which lead to FDI (far more than 50\% ).

Even though the underlying framework only considers a representative firm, the last result has crucial implications for sectoral first time market entry investments. Accordingly, sectors with higher productivity growth should exhibit a higher share of FDI as first time entry mode, since the range of relative cost constellations which promote FDI is relatively larger. 


\subsection{FDI or Export with Uncertain Productivity Growth}

Although the introduction of productivity growth accounts for empirically important effects still one crucial aspect is neglected. Productivity growth is not a deterministic phenomenon but represents a continuously volatile process over time (Baily et al., 2001). As a consequence of this stochastic characteristic, the investor is no longer confronted with a simple choice problem between two types of market entry over time. Additionally, he has to adjust his expectations to the prevailing continuous productivity uncertainty. A natural and convenient way to extend the previous settings, in order to account for productivity uncertainty, is the introduction of a Geometric Brownian motion represented by (11) whose solution is derived as

$$
\vartheta_{t}=\vartheta_{0} e^{\int_{0}^{T}\left(\alpha-\frac{1}{2} \sigma^{2}\right) d t+\int_{0}^{T} \sigma d z t}
$$

Within this final framework the investor assesses any uncertain investment with respect to the capital market where an appropriate return (including a risk-premium) is derived. In order to evaluate the appropriate investment return for both market entry modes it is assumed that there exists an asset on a complete capital market which is perfectly correlated with the latter Geometric Brownian motion. ${ }^{8}$ Furthermore, this replication asset is assumed to pay no dividends and therefore, its complete return can be attributed to its capital gain. With reference to the capital asset pricing model (CAPM) the risk adjusted expected return $\mu$ of such an investment is derived from

$$
\mu_{i}=r+\frac{\left(r_{M}-r\right)}{\sigma_{M}} v_{c M} \sigma_{i}
$$

where $v_{C M}$ specifies the correlation between the spanned asset and the market portfolio. $r_{M}$ and $\sigma_{M}$ represent the expected return and the volatility of the latter one. Within this framework the market price of risk is measured as $\frac{r_{M}-r}{\sigma_{M}}$ and is referred to as the Sharpe ratio (Sharpe, 1964). Based on the linear relationship in equation (45) it is possible to derive an appropriate risk-adjusted expected rate of return for any degree of uncertainty described by $\sigma$.

Once the adjusted expected return $\mu$ is known, it is possible to derive the risk-adjusted opportunity costs in order to evaluate the export and FDI strategy under uncertainty. In equilibrium, the

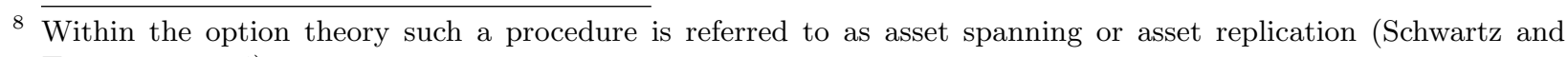
Trigeorgis, 2004)
} 
difference between the risk-adjusted return $\mu$ and the deterministic growth rate $\alpha$ represents the rate of opportunity costs with

$$
\delta_{u}=\mu-\alpha
$$

For a positive $\delta_{u}$, an investment exhibits an expected capital gain rate $\alpha$ which is lower than the risk-adjusted rate of return $\mu$. Therefore, by delaying the investment the investor incurs an opportunity cost rate of $\delta_{u}$. Consequently, for a high opportunity cost rate the immediate execution of the respective investment is more likely because the corresponding option value will be low, due to a low $\alpha$.

Since in the underlying framework the cash-flows $M_{i} \vartheta_{i}$ increase exponentially in $\vartheta$ for $\kappa>1$, it is necessary to determine the corresponding risk-adjusted growth rate $\alpha_{u}^{\prime}$, which is derived as

$$
\alpha_{u}^{\prime}=\alpha \kappa+\frac{1}{2} \kappa(\kappa-1) \sigma^{2}
$$

Therefore, for both market entry modes the expected value of the cash-flows at time $t$ can be calculated by

$$
\mathbb{E}\left(M_{i} \vartheta_{t}^{\kappa}\right)=M_{i} \vartheta_{0}^{\kappa} e^{\alpha \kappa+\frac{1}{2} \kappa(\kappa-1) \sigma^{2}} \quad \text { with } \quad i \in\{E, F\}
$$

Equation (48) shows that for linear periodical cash-cash flows $(\kappa=1)$ in $\vartheta$, the expected value is independent of the parameter $\sigma$. The investor expects the same profits as in the previous deterministic case. However, for $\kappa>1$ the expected profit-flows increase and are bigger the higher the uncertainty in the productivity development becomes. This disproportionate expectation is driven by Jensen's inequality and has a positive impact on the current gross investment value in both market entry modes. Given the risk-adjusted growth rate $\alpha_{u}^{\prime}$ the risk-adjusted total rate of return results as

$$
\mu_{u}^{\prime}=r+\kappa(\mu-r)
$$

and the risk-adjusted discount rate can be derived as

$$
\delta_{u}^{\prime}=r-\left(r-\delta_{u}\right) \kappa-\frac{1}{2} \kappa(\kappa-1) \sigma^{2} .
$$


Finally, the net present investment values of both market entry modes associated with uncertain productivity growth result as

$$
\begin{aligned}
& V_{i_{u}}(\vartheta)-I_{i}=\int_{0}^{\infty} M_{i} \vartheta^{\kappa} e^{\alpha_{u}^{\prime} t} e^{-\mu^{\prime} t} d t-I_{i} \\
& V_{i_{u}}(\vartheta)-I_{i}=\frac{M_{i_{u}} \vartheta^{\kappa}}{r-\left(r-\delta_{u}\right) \kappa-\frac{1}{2} \kappa(\kappa-1) \sigma^{2}}-I_{i} \\
& \text { with } \vartheta=\vartheta_{0} \quad \text { and } \quad i \in\{E, F\} .
\end{aligned}
$$

For $\kappa=1$ and $\sigma=0$ the two net present value functions increase linearly in $\vartheta$ and they exactly behave as in the deterministic scenario, because the opportunity cost rates are equal $\left(\delta_{u}^{\prime}=\delta_{c}^{\prime}\right){ }^{9}$ However, driven by Jensen's inequality, both expected present investment values are higher than in the previous scenario $\left(V_{i_{u}}(\vartheta)>V_{i}(\vartheta)\right)$ if the cash-flows are convex in $\vartheta$ and if the productivity growth is accompanied by uncertainty $(\sigma>0)$. Formally, the additional term $\frac{1}{2} \kappa(\kappa-1) \sigma^{2}$ accounts for these additional expected gains in the investment values.

In figure 5 the two net present value functions shift to the north if productivity growth is associated with uncertainty. Consequently, the intersection points between the horizontal axis and the export and FDI investment value functions appear at lower productivity levels with $\vartheta_{E_{u}}^{0}$ and $\vartheta_{F_{u}}^{0}$ representing the critical thresholds for positive values respectively for both market entry modes. However, as in the previous scenario both market entry modes are associated with a timing problem as the periodical cash-flows rise over time whereas the fixed costs $I_{i}$ are unchanged and appear only in the first investment period. Therefore, in order to assess whether there exits a value of waiting, it is necessary to determine the option values of both investment strategies.

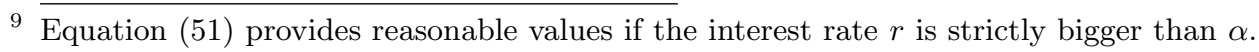


The general functional form of the option values for both market entry strategies results as

$$
\begin{aligned}
& F_{i_{u}}(\vartheta)=A_{i 1_{u}} \vartheta^{\beta_{1_{u}}}+A_{i 2_{u}} \vartheta^{\beta_{2_{u}}} \\
& \text { with } \\
& \beta_{1_{u}}=\frac{1}{2}-\frac{r-\delta_{u}}{\sigma^{2}}+\sqrt{\left[\frac{r-\delta_{u}}{\sigma^{2}}-\frac{1}{2}\right]^{2}+\frac{2 r}{\sigma^{2}}}>1 \\
& \beta_{2_{u}}=\frac{1}{2}-\frac{r-\delta_{u}}{\sigma^{2}}-\sqrt{\left[\frac{r-\delta_{u}}{\sigma^{2}}-\frac{1}{2}\right]^{2}+\frac{2 r}{\sigma^{2}}}<0 .
\end{aligned}
$$

The optimal cut-offs $\vartheta_{i_{u}}^{*}$ and the two unknown $A_{i j_{u}}$ can be determined by defining appropriate boundary conditions. If the current productivity level $\vartheta$ approaches zero, the option value of an uncertain investment should also tend to zero, as the probability of a sufficient increase in the future is low. Therefore, the first boundary condition states

$$
F_{i_{u}}(0)=0
$$

If the productivity level reaches the optimal cut-off level, the investor is indifferent between delaying the uncertain investment (keeping the option alive) and executing the project by investing the sunk costs $I_{i}$. As a consequence, the second condition is the matching condition which captures the indifference at $\vartheta_{i_{u}}^{*}$ with

$$
F_{i_{u}}\left(\vartheta_{i_{u}}^{*}\right)=V_{i}\left(\vartheta_{i_{u}}^{*}\right)-I_{i}
$$

Finally, in order to find an optimal threshold value for $\vartheta$ the two functions need to be tangent in the optimum. Tangency can be accounted for by imposing the smooth pasting condition with

$$
\frac{\partial F\left(\vartheta_{i_{u}}^{*}\right)}{\partial \vartheta}=\frac{\partial V\left(\vartheta_{i_{u}}^{*}\right)}{\partial \vartheta}
$$

The first boundary condition necessitates that $A_{i 2_{u}}=0$ as $\beta_{2_{u}}$ is negative. Therefore, the option functions for both market entry modes are reduced to

$$
\begin{aligned}
& F_{i_{u}}(\vartheta)=A_{i_{u}} \vartheta^{\beta_{u}} \\
& \text { with } \beta_{u}=\beta_{1_{u}} \text { and } i \in\{E, F\} .
\end{aligned}
$$


By using the remaining two conditions the option value functions result as

$$
\begin{aligned}
F_{i_{u}}(\vartheta) & =A_{i_{u}} \vartheta^{\beta_{u}} \\
& =M_{i}^{\frac{\beta_{u}}{\kappa}} I_{i}^{1-\frac{\beta_{u}}{\kappa}} \Omega \vartheta^{\beta_{u}} \\
& \text { with } \Omega=\frac{1}{\delta_{u}^{\prime}}\left(\frac{\beta_{u} \delta_{u}^{\prime}}{\beta_{u}-\kappa}\right)^{1-\frac{\beta_{u}}{\kappa}}-\delta_{u}^{\prime}\left(\frac{\beta_{u} \delta_{u}^{\prime}}{\beta_{u}-\kappa}\right)^{-\frac{\beta_{u}}{\kappa}} \text { and } i \in\{E, F\} .
\end{aligned}
$$

Finally, the cut-off productivity level for each market entry mode is derived as

$$
\vartheta_{E u}^{*}=\sqrt[\kappa]{\frac{\beta_{u}}{\beta_{u}-\kappa} \frac{I_{E} \delta_{u}^{\prime}}{M_{E}}} \text { and } \vartheta_{F u}^{*}=\sqrt[\kappa]{\frac{\beta_{u}}{\beta_{u}-\kappa} \frac{I_{F} \delta_{u}^{\prime}}{M_{F}}}
$$

These two equilibrium productivity levels differ from the previous cut-offs under certainty only in the magnitude of the two parameters $\delta_{u}^{\prime}$ and $\beta_{u}$, which are affected by the productivity uncertainty $\sigma .{ }^{10}$ The magnitude of $\beta_{u}$ is derived form the fundamental quadratic equation

$$
\Psi=\frac{1}{2} \sigma^{2} \beta_{u}\left(\beta_{u}-1\right)+\left(r-\delta_{u}\right) \beta_{u}-r=0
$$

and decreases in $\sigma$

$$
\frac{\partial \beta_{u}}{\partial \sigma}<0
$$

The risk-adjusted discount rate $\delta_{u}^{\prime}$ turns out to be the negative expression of $\Psi$. For reasonable results $\delta_{u}^{\prime}$ needs to be strictly positive. Therefore, $\kappa$ must lie between the two roots and consequently, this last requirement necessitates that

$$
\beta_{u}>\kappa>0
$$

Based on these two relationships it is possible to analyze the underlying market entry problem as in the previous scenarios. The ordinal rank between the two productivity cut-offs is independent of the growth rate $\alpha_{u}^{\prime}$ and the extent of uncertainty $\sigma$. It is only influenced by the comparative

\footnotetext{
${ }^{10} \overline{\text { For } \sigma=0 \text { the opportunity cost rate } \mu-\alpha=\delta_{u}}=r-\alpha=\delta_{c}$.
} 
fixed cost and marginal cost advantage with

$$
\frac{\vartheta_{E}^{*}}{\vartheta_{F}^{*}} \lesseqgtr 1 \quad \text { if } \quad \frac{I_{E}}{I_{F}} \lesseqgtr\left(\frac{w_{F}}{w_{E} \tau^{\frac{1}{\theta}}}\right)^{\frac{\nu \theta}{1-\nu \theta}} .
$$

Therefore, for all relative cost constellations in figure 7, which are above the dotted line, the

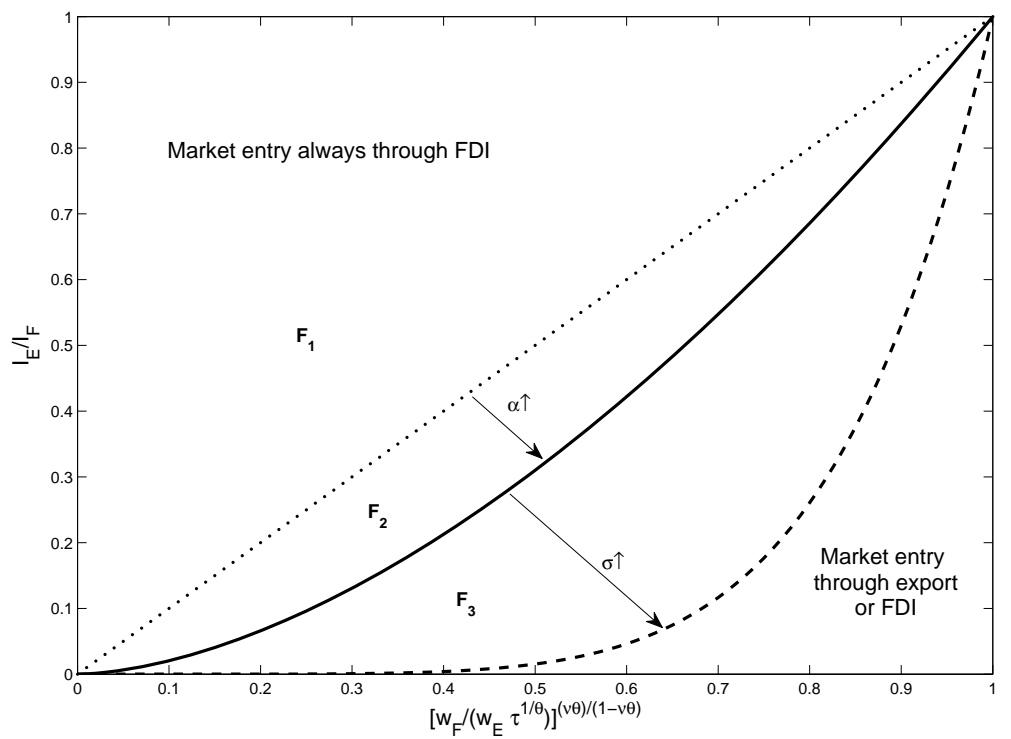

Figure 7: Relative Cost Constellations \& Uncertain Productivity Growth

cut-off level for the FDI mode will always be lower than the export threshold. The opposite holds for cost patterns below the diagonal curve. The intuition behind this result is that uncertainty influences both entry cut-offs proportionally and does not distort the relationship which has been derived in the deterministic case. However, for the final entry decision it is the option values which determine the optimal market entry mode for given cost constellations.

It is possible to describe the relationship between the two option value functions by

$$
\frac{F_{E}(\vartheta)}{F_{F}(\vartheta)} \lesseqgtr 1 \quad \text { if } \quad\left(\frac{w_{F}}{w_{E} \tau^{\frac{1}{\theta}}}\right)^{\frac{\nu \theta}{1-\nu \theta}} \gtreqless \frac{I_{E}}{I_{F}}\left(\frac{I_{E}}{I_{F}}\right)^{-\frac{\kappa}{\beta_{u}}},
$$

which is equal to the relationship in the previous scenario except the exponent $\beta_{u}$ which is risk sensitive. According to the fundamental equation (63) for $\sigma=0$

$$
\beta_{u}=\frac{r}{r-\delta_{c}}=\frac{r}{\alpha}=\beta_{c},
$$


which proves the consistency of the model as the result is equivalent to the previous certain case. In figure 7 the areas $F_{1}$ and $F_{2}$ are equal to the areas $C_{1}$ and $C_{3}$ in figure 6 since they represent the deterministic case. By taking the two relationships (64) and (65) into account the risk driven adjustments of the option values and of equation (67) are straightforward. With an increase in productivity uncertainty, $\beta_{u}$ decreases and becomes smaller than $\beta_{c}$. Graphically, the continuous line in figure 7 which represents relationship (67) becomes more convex as depicted by the dashed line. As a consequence, the range of relative cost constellations which enforce FDI over time increases by the area $F_{3}$. Differently expressed, a volatile growth in productivity broadens the range of cost constellations favoring FDI as the first time market entry strategy compared with a deterministic growth development. Uncertainty therefore acts as a compound force for the derived deterministic growth effects.

\section{Result 3:}

For $I_{E}<I_{F}$ and $w_{E} \tau^{\frac{1}{\theta}}>w_{F}$ the range of relative cost constellations which enforce FDI as the optimal market entry mode is strictly bigger if productivity growth $d \vartheta_{t}$ is associated with uncertainty. For $\sigma \rightarrow \infty$, FDI becomes the only relevant market entry mode.

\section{The Timing Effects of Uncertainty}

The increasing dominance of the FDI mode as the optimal first time market entry strategy due to an increase in $\sigma$ implies according to the common real option theory an increase in the market entry time (Dixit and Pindyck, 1994). ${ }^{11}$ However, in contrast to the previous deterministic case it is no longer possible to quantify the exact market entry time $T_{i}^{*}$ for both market entry modes as the investor's decision is based on a stochastic process. But, it is possible to calculate the expected first time entry $\mathbb{E}\left(T_{i}^{*}\right)$, if the initial productivity level $\vartheta_{0}$ and the cut-off productivity $\vartheta_{i}^{*}$ are known. The corresponding time $T_{i}^{*}$ at which the stochastic process reaches its trigger value $\vartheta_{i}^{*}$ represents the first passage time.

\footnotetext{
${ }^{11}$ Dixit and Pindyck (1994) assume in their illustrative examples that the risk adjusted return rate is invariant in $\sigma$ which is the case for linear profit functions. In such cases, there is a positive relationship between the first time market entry $T_{i}^{*}$ and $\sigma$.
} 
By using the Girsanov theorem ${ }^{12}$ it is possible to derive the probability density function of $T_{i}^{*}$ as

$$
\begin{aligned}
& f\left(T_{i}^{*}, \vartheta_{0}, \vartheta_{i}^{*}\right)=\frac{\ln \left(\frac{\vartheta_{i}^{*}}{\vartheta_{0}}\right)}{\sqrt{2 \pi \sigma^{2} T_{i}^{* 3}}} e^{-\frac{\left(\ln \left(\frac{\vartheta_{i}^{*}}{\vartheta_{0}}\right)-\left(\alpha-\frac{1}{2} \sigma^{2}\right) T_{i}^{*}\right)^{2}}{2 \sigma^{2} T_{i}^{*}}} \\
& \text { with } \vartheta_{i}^{*}>\vartheta_{0}
\end{aligned}
$$

which is also referred to as the Inverse Gaussian distribution. ${ }^{13}$ The Laplace transform of $T_{i}^{*}$ is then given by (see Ross, 1996; Proposition 8.4.1)

$$
\mathbb{E}\left(e^{-\lambda T_{i}^{*}}\right)=\int_{0}^{\infty} e^{-\lambda T_{i}^{*}} f\left(T_{i}^{*}\right) d T_{i}^{*}=e^{-\left(\sqrt{\left(\alpha-\frac{1}{2} \sigma^{2}\right)^{2}+2 \sigma^{2} \lambda}-\left(\alpha-\frac{1}{2} \sigma^{2}\right)\right) \frac{\ln \left(\frac{\vartheta_{i}^{*}}{\vartheta_{0}}\right)}{\sigma^{2}}} .
$$

and can be used to determine the expected time before market entry as

$$
\mathbb{E}\left(T_{i}^{*}\right)=\int_{0}^{\infty} T_{i}^{*} f\left(T_{i}^{*}\right) d T_{i}^{*}=-\lim _{\lambda \rightarrow 0} \frac{\partial \mathbb{E}\left(e^{-\lambda T_{i}^{*}}\right)}{\partial \lambda}=\frac{\ln \left(\frac{\vartheta_{i}^{*}}{\vartheta_{0}}\right)}{\alpha-\frac{1}{2} \sigma^{2}}
$$

More precisely, the expected time before market entry results in both modes as (see Karatzas and Shreve, 1991)

$$
\mathbb{E}\left(T_{i}^{*}\left(\vartheta=\vartheta_{i}^{*}\right)\right)= \begin{cases}\frac{1}{\alpha-\frac{1}{2} \sigma^{2}} \ln \left(\frac{\vartheta_{i}^{*}}{\vartheta_{0}}\right) & \text { if } \quad \alpha>\frac{1}{2} \sigma^{2} \\ \infty & \text { if } \quad \alpha \leq \frac{1}{2} \sigma^{2}\end{cases}
$$

with $\vartheta_{i}^{*}>\vartheta_{0}$ and $i \in\{E, F\}$.

Equation (72) shows that for $\sigma \in(0, \sqrt{2 \alpha})$ there exists a finite market entry time. However, if productivity growth $\alpha$ is lower than $\frac{1}{2} \sigma^{2}$ or equal to zero, market entry might not be realized since $\mathbb{E}\left(T_{i}^{*}\right)$ diverges. ${ }^{14}$

Within the proximity-concentration trade-off framework it is again possible to derive a relationship between relative fixed and variable costs which determines whether the expected market

\footnotetext{
${ }_{12}$ A detailed derivation is offered by Karatzas and Shreve (1991, p.196) or by Karlin and Taylor (1975, p.363).

${ }^{13}$ The name "inverse gaussian distribution" stems form the inverse relationship between the cumulant generating functions of these distributions and those of Gaussian distributions.

${ }^{14}$ A detailed discussion about the peculiarities of the inverse gaussian distribution can be found in Johnson, Kotz, and Balakrishnan (1995) or Dixit (1993).
} 
entry time in the export mode is smaller (equal to, higher) than in the FDI mode.

It follows from equation (72) that

$$
\mathbb{E}\left(T_{E}^{*}\right) \lesseqgtr \mathbb{E}\left(T_{F}^{*}\right) \quad \text { if } \quad \frac{\vartheta_{E}^{*}}{\vartheta_{F}^{*}} \lesseqgtr 1
$$

which equals relation (66) and which is fulfilled, if

$$
\frac{I_{E}}{I_{F}} \lesseqgtr\left(\frac{w_{F}}{w_{E} \tau^{\frac{1}{\theta}}}\right)^{\frac{\nu \theta}{1-\nu \theta}} .
$$

Combining this result with the previous outcomes summarized in figure 7 it can be seen that for all relative cost constellations above the diagonal line (area $F_{1}$ with $\vartheta_{E}^{*}>\vartheta_{F}^{*}$ ), the FDI mode's expected market entry time $\mathbb{E}\left(T_{F}^{*}\right)$ is always less than in the export mode. Simultaneously, FDI turns out to be the optimal entry strategy due to its higher option value. Inversely, for all relative cost patterns below the diagonal line, the optimal FDI productivity cut-off strictly exceeds the export cut-off. Therefore, if the new foreign market is served through exports, its expected market entry will appear earlier with respect to the FDI mode. However, for all cost constellations represented through the areas $F_{1}$ and $F_{2}$, which are driven by $\alpha$ and $\sigma$, the FDI option value is strictly superior to the export option value and consequently the investor is likely to serve the market through FDI in $\mathbb{E}\left(T_{F}^{*}\right)$, which is strictly higher than $\mathbb{E}\left(T_{E}^{*}\right)$, as illustrated by (73). Due to the abolition of such a profitable export strategy for the sake of a more profitable future FDI investment, a potential earlier expected market entry is prolonged by $\Delta \mathbb{E}\left(T^{*}\right)=\mathbb{E}\left(T_{F}^{*}\right)-\mathbb{E}\left(T_{E}^{*}\right)$. Since the prolongation of the expected market entry is caused by the negligence of a less profitable export mode over time, I refer to this first timing effect as prolongation of market entry time by negligence. ${ }^{15}$

\section{Result 4:}

For $I_{E}<I_{F}$ and $w_{E} \tau^{\frac{1}{\theta}}>w_{F}$ with $\alpha>0$ and $\sigma>0$, there exists a range of relative cost constellations which leads to a prolongation of the expected market entry time by $\Delta \mathbb{E}\left(T^{*}\right)=$ $\mathbb{E}\left(T_{F}^{*}\right)-\mathbb{E}\left(T_{E}^{*}\right)$, due to the negligence of a profitable export mode in $T_{E}^{*}<T_{F}^{*}$.

\footnotetext{
${ }_{15}$ This result is based on the assumption that the initial productivity level $\vartheta_{0}$ is smaller than $\vartheta_{i}^{*}$ with $i=\{E, F\}$. For all cost constellations below the diagonal line in figure 7 , the optimal market entry mode will also depend on the current productivity level $\vartheta_{0}$. If e.g. the current productivity level is above both cut-off productivity levels and therefore enforcing FDI, there is no timing issue and no prolongation of entry time by negligence.
} 
By integrating the probability density function (69) it is possible to derive the corresponding cumulative distribution functions as

$G\left(T_{i}^{*}, \vartheta_{0}, \vartheta_{i}^{*}\right)=N\left(-\frac{\ln \left(\frac{\vartheta_{i}^{*}}{\vartheta_{0}}\right)+\left(\alpha-\frac{1}{2} \sigma^{2}\right) T_{i}^{*}}{\sigma \sqrt{T_{i}^{*}}}\right)+e^{\left(\frac{2\left(\alpha-\frac{1}{2} \sigma^{2}\right) \ln \left(\frac{\vartheta_{i}^{*}}{\vartheta_{0}}\right)}{\sigma^{2}}\right)} N\left(-\frac{\ln \left(\frac{\vartheta_{i}^{*}}{\vartheta_{0}}\right)-\left(\alpha-\frac{1}{2} \sigma^{2}\right) t}{\sigma \sqrt{t}}\right)$

with $\vartheta_{0}<\vartheta_{i}^{*}$ and $i \in\{E, F\}$.

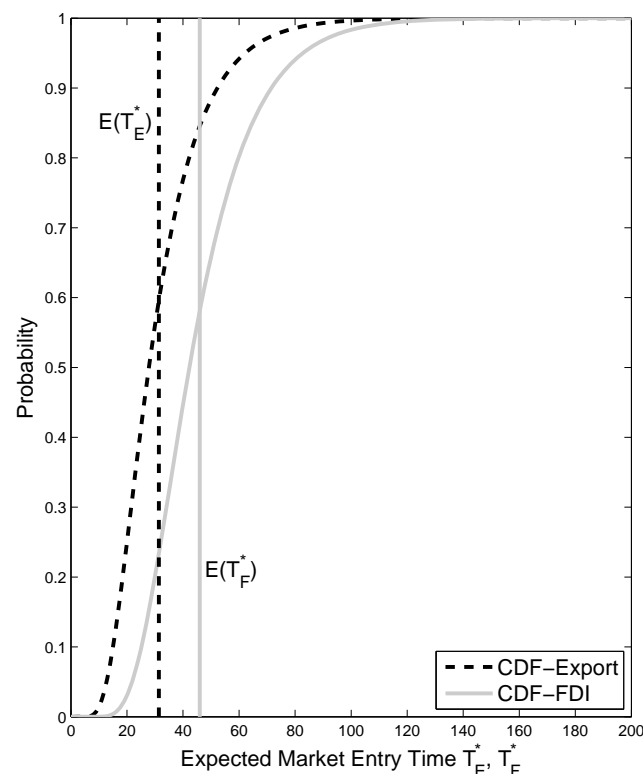

(a) $\vartheta_{E}^{*}<\vartheta_{F}^{*}, \alpha=0.04, \vartheta_{0}=1, \sigma=0.1$, but $F_{F}(\vartheta)>F_{E}(\vartheta)$ with $\kappa=1$

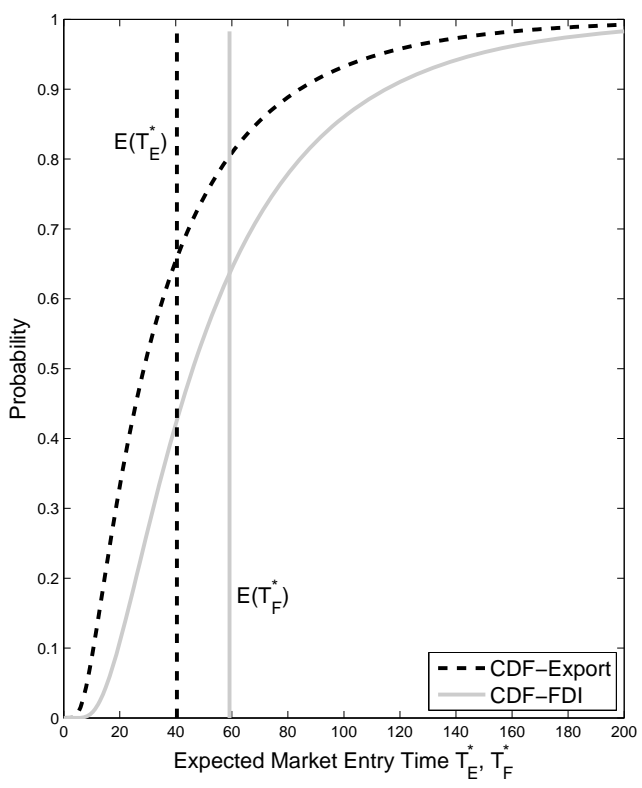

(b) $\vartheta_{E}^{*}<\vartheta_{F}^{*}, \alpha=0.04, \vartheta_{0}=1, \sigma=0.16$, but $F_{F}(\vartheta)>F_{E}(\vartheta)$ with $\kappa=1$

Figure 8: Cumulative Distribution Functions of $T_{i}^{*}$.

Panel a) in figure 8 represents the cumulative distribution functions of both investment strategies for a relative cost constellation which leads to a productivity cut-off ranking with $\vartheta_{E}^{*}<\vartheta_{F}^{*}$. The vertical dashed line represents the export mode's expected market entry time and the s-shaped curve its cumulative distribution function. The continuous curves represent the FDI mode. In the underlying example the export mode exhibits a first-order stochastic dominance over the FDI strategy. Differently expressed, for any market entry time $T_{i}^{*}$, the probability of market entry through exports will always be higher than in the FDI case. However, for the chosen relative cost pattern, the FDI mode exhibits a higher option value (see figure 7 , areas $F_{2}, F_{3}$ ) and therefore 
the investor will neglect the export market entry for the sake of the FDI mode. The distance between $\mathbb{E}\left(T_{F}^{*}\right)$ and $\mathbb{E}\left(T_{E}^{*}\right)$ in figure 8 represents the prolongation of market entry by negligence. Inversely, it can be concluded that for relative cost patterns which lead to a productivity cut-off ranking with $\vartheta_{F}^{*}<\vartheta_{E}^{*}$, the FDI mode has a first-order stochastic dominance over the export mode and there will be no market entry prolongation.

By considering the partial derivative of equation (71) with respect to $\sigma$ it is possible to assess the impact of a volatility change in productivity on the expected market entry time. The differential results as

$$
\begin{aligned}
& \frac{\partial \mathbb{E}\left(T_{i}^{*}\right)}{\partial \sigma}=\sigma \frac{1}{\left(\alpha-\frac{1}{2}\right)^{2}} \ln \left(\frac{\vartheta_{i}^{*}}{\vartheta_{0}}\right)+\frac{1}{\left(\alpha-\frac{1}{2} \sigma^{2}\right)} \frac{1}{\vartheta_{i}^{*}} \frac{\partial \vartheta_{i}^{*}}{\partial \sigma} \\
& \text { with } \frac{\vartheta_{i}^{*}}{\vartheta_{0}}>1 \text { and } \alpha>\frac{1}{2} \sigma^{2} .
\end{aligned}
$$

Thus, whether a change in uncertainty results in a positive or negative effect on the expected market entry time, decisively depends on the partial differential on the right hand side of equation (75). A change in uncertainty affects the optimal productivity levels $\vartheta_{i}^{*}$ through two channels. The first effect of an increase in $\sigma$ is a rise in the option value of each market entry mode which is captured by

$$
\frac{\partial\left(\frac{\beta_{u}}{\beta_{u}-\kappa}\right)}{\partial \sigma}>0 \text { for } \quad \kappa \geq 1
$$

The intuition for this monotonic positive effect is that an increase in uncertainty, incentivises the postponement of the investment decision into the future (higher $\vartheta_{i}^{*}$ ) in order to gain additional information on the productivity development.

The second effect is a change in the expected investment value $V_{i}(\vartheta)$ which itself depends on the adjusted discount rate $\delta_{u}^{\prime}$.

For linear periodical cash-flows $(\kappa=1)$ the discount rate becomes independent of $\sigma$ with

$$
\frac{\partial \delta_{u}^{\prime}}{\partial \sigma}=0
$$

Summing up theses two effects, in this particular case both market entry modes' expected market entry time strictly increases in $\sigma$. Furthermore, since the productivity cut-offs of both entry 
modes additionally depend on the respective variable and fixed costs, the extent of their expected market entry time adjustments differs due to different cost structures. An increase in $\sigma$ leads e.g. to a stronger rise in the FDI mode's expected market entry time

$$
\begin{aligned}
\frac{\partial \mathbb{E}\left(T_{F}^{*}\right)}{\partial \sigma} & >\frac{\partial \mathbb{E}\left(T_{E}^{*}\right)}{\partial \sigma}>0 \\
\text { if } & \\
\frac{I_{E}}{M_{E}} & <\frac{I_{F}}{M_{F}},
\end{aligned}
$$

which is the case for all relative cost patterns below the diagonal line in figure 7 . Figure 8 represents such a relative cost constellation where panel b) differs from panel a) only in $\sigma$. As a result of the uncertainty increase, the expected market entry time is prolonged in both modes. However, the change in the FDI mode turns out to be higher than in the export mode with

$$
\Delta \mathbb{E}\left(T_{F}^{*}\right)>\Delta \mathbb{E}\left(T_{E}^{*}\right)
$$

Finally, three crucial effects can be identified within the proximity-concentration trade-off framework, associated with an increase in $\sigma$ :

- An increase in the expected market entry times in both modes.

- An increase in the range of relative cost constellations in figure 7 favoring FDI as the optimal market entry mode.

- A higher increase in the expected market entry time in the FDI mode.

As a consequence, market entry through FDI becomes more likely, but the likeliness of market entry per period decreases due to postponement.

\section{Result 5:}

For $I_{E}<I_{F}$ and $w_{E} \tau^{\frac{1}{\theta}}>w_{F}$ with $\kappa=1$, a rise in productivity volatility $\sigma$ increases the likelihood of first time market entry through FDI but prolongs the expected market entry time $\mathbb{E}\left(T_{F}^{*}\right)$. The probability of first time market entry in $T$ decreases.

These comparative static findings are compliant with the general real option literature according to which uncertainty monotonically increases the market entry time (Dixit and Pindyck, 1994). 
However, the described relationship turns out to be idiosyncratic to linear profit functions. For convex profit functions $(\kappa>1)$ an increase in productivity uncertainty does not only affect the optimal cut-off level negatively (increase in $\vartheta_{i}^{*}$ ) but additionally exhibits a countervailing effect. In such a case, the expected profits of both market entry modes rise, due to Jensen's inequality which reduces the optimal cut-off levels $\vartheta_{i}^{*}$. This positive adjustment is captured by the partial differential of the adjusted discount rate

$$
\frac{\partial \delta_{u}^{\prime}}{\partial \sigma}=\sigma \kappa-\sigma \kappa^{2}<0
$$

which is monotonically decreasing in $\sigma$. The intuition for this effect is that an investor can expect higher profits associated with productivity changes and as a consequence the adjusted discount rate increases the costs of waiting if $\sigma$ increases. Therefore, for $\kappa>1$ the total impact of uncertainty on the expected market entry time depends on the modulus of the two effects. For

$$
\left|\frac{\partial\left(\frac{\beta_{u}}{\beta_{u}-\kappa}\right)}{\partial \sigma}\right|>\left|\frac{\partial \delta_{u}^{\prime}}{\partial \sigma}\right|,
$$

the expected market entry time also increases in $\sigma$ for $\kappa>1$, however

$$
\left.\frac{\partial \mathbb{E}\left(T_{i}^{*}\right)}{\partial \sigma}\right|_{\kappa=1}>\left.\frac{\partial \mathbb{E}\left(T_{i}^{*}\right)}{\partial \sigma}\right|_{\kappa>1}
$$

due to the negative effect in $\delta_{u}^{\prime}{ }^{16}$

For specific parameter values, Jensen's inequality dominates the total effect of an increase in uncertainty and for such cases the expected market entry time can decrease. Plotting the expected market entry time with respect to $\sigma$ results therefore, in a u-shaped function (figure 9).

Differently expressed, for low levels of uncertainty the expected market entry time in both modes decrease whereas for high levels of uncertainty, a shift in $\sigma$ increases $\mathbb{E}\left(T_{i}^{*}\right)$. Figure 9 shows that for high productivity growth rates $\alpha$ the likeliness of a decrease in the expected market entry time is higher than in cases with low growth rates. Technically, the range of values in which $\mathbb{E}\left(T_{i}^{*}\right)$ decreases in $\sigma$ becomes bigger the higher the growth rate is $\left(\sigma_{0}<\sigma_{1}\right.$, in figure 9$)$. The intuition for this result is that companies associated with high growth rates may appreciate a certain extent of productivity uncertainty and enter the market earlier. Whereas, firms confronted with

\footnotetext{
${ }_{16}$ A detailed analysis can be found in Wong (2007).
} 


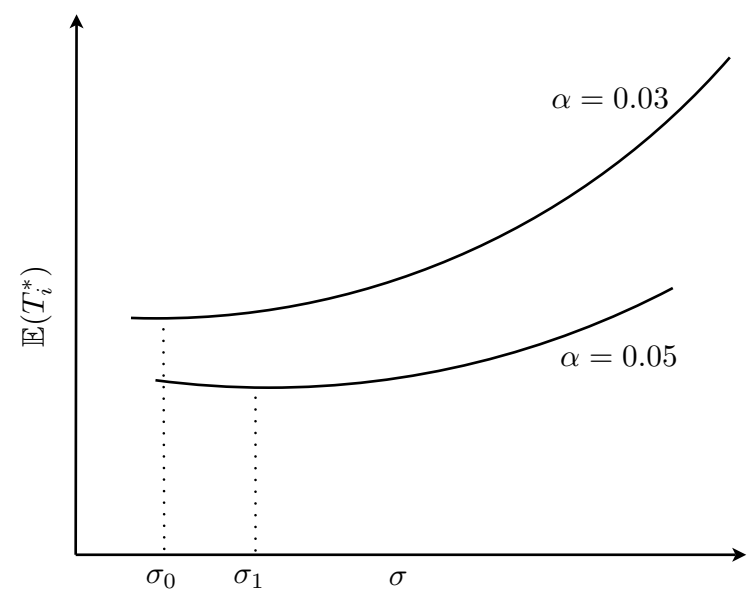

Figure 9: Expected Market Entry Time Pattern

low growth rates tend to dislike uncertainty and postpone their investment decision further into the future the higher the volatility.

Finally, within the proximity-concentration trade-off framework, a reduction of the expected market entry time due to an increase in $\sigma$ is still accompanied by a rise in the range of relative cost constellations in figure 7 which enforce FDI as the optimal entry strategy. Additionally, one can conclude that for a firm associated with a high productivity growth rate, a rise in uncertainty may lead to an earlier market entry.

\section{Result 6:}

For $I_{E}<I_{F}$ and $w_{E} \tau^{\frac{1}{\theta}}>w_{F}$ with $\kappa>1$, a rise in productivity volatility $\sigma$ increases the likelihood of first time market entry through FDI. There exists a range of uncertainty $0<\sigma<\sigma_{0}$ in which the market entry is preponed. For these parameter constellations the likeliness of market entry per period increases.

\section{The Degree of Competition and Comparative Statics}

A crucial aspect for an investor's first time market entry decision is the degree of competition in the potential destination country. Within the established framework we can measure the extent of competition by considering the inverse of the country specific mark-up $\nu$. Demand turns out to be flat if $\nu$ approaches one. In such a case, the investor holds a low degree of market power as the substitutability between the differentiated goods $X_{i}$ is high. 


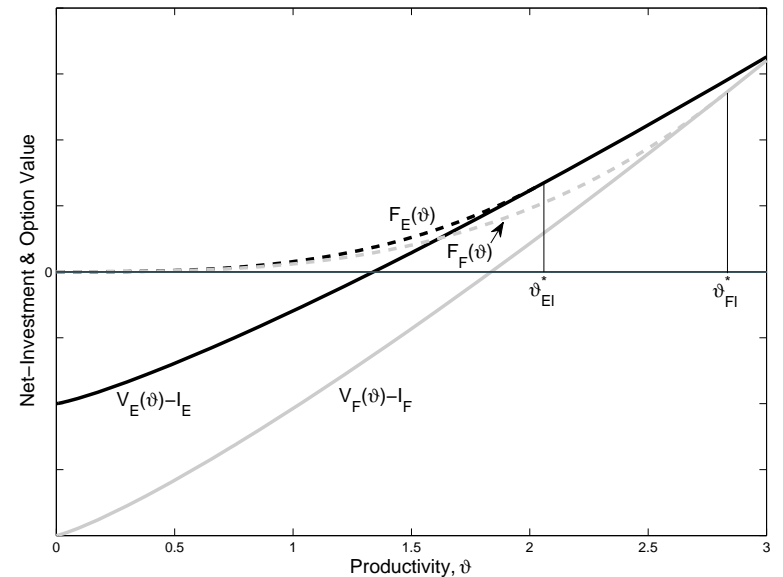

(a) Country A (Low Competition) $\nu_{A}=0.75$

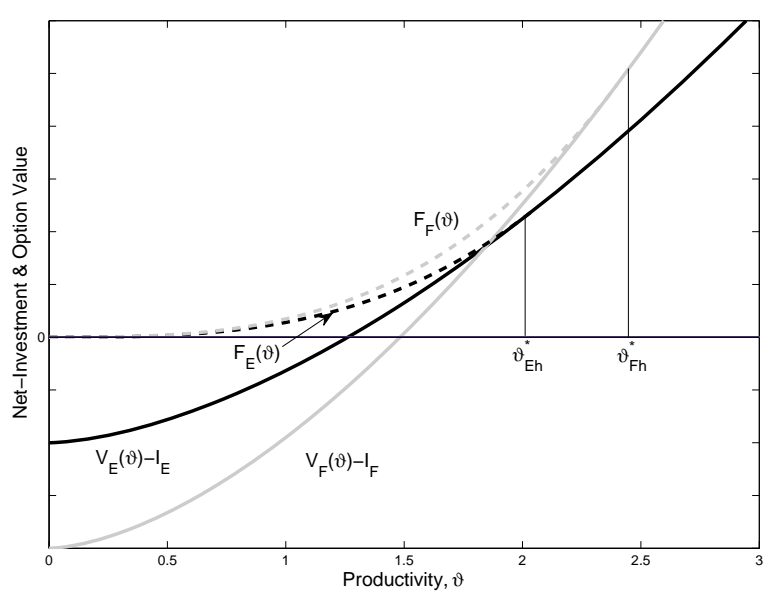

(b) Country B (High Competition) $\nu_{B}=0.9$

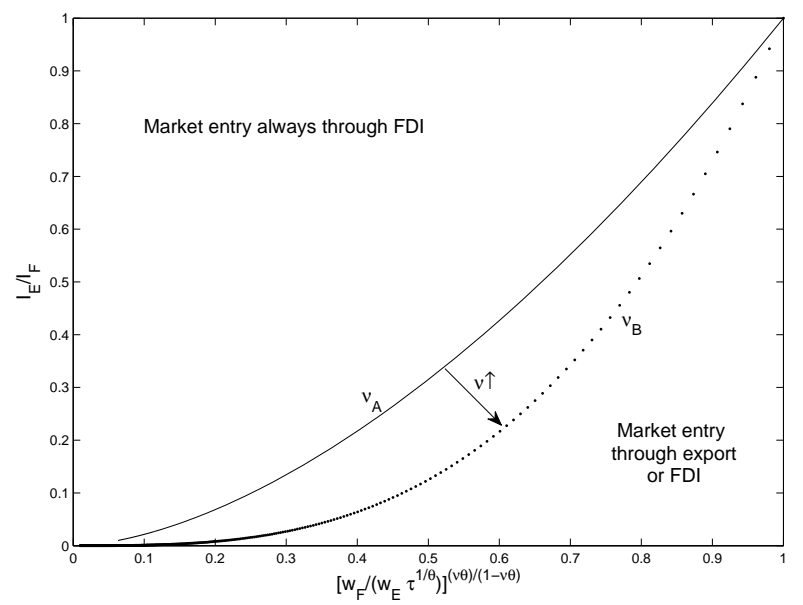

(c) Degree of Competition \& Relative Cost Patterns

Figure 10: Competition Effects

Figure 10 depicts the export and FDI value functions in two different countries. The investor is confronted with exactly the same cost patterns in both foreign markets. ${ }^{17}$ The only difference appears in the degree of competition, with country A exhibiting a lower competition between the differentiated goods $X_{i}$ than country B $\left(\nu_{A}<\nu_{B}\right)$. In the low competition case, the given relative cost pattern leads to an export productivity cut-off $\vartheta_{E l}^{*}$ which is lower than the FDI cut-off. Simultaneously, given the degree of competition, the upper envelope function in panel a) turns out to be dominated by the option and investment value function of the export mode. Assuming that the initial productivity level $\vartheta_{0}$ is below $\vartheta_{E l}^{*}$, the investor will definitely serve the

${ }^{17}$ In both markets the investor is confronted with the following cost structure: $\frac{I_{E}}{I_{F}}=2, \tau=1.3, \theta=0.5, \frac{w_{F}}{w_{E}}=1, r=$ $0.06, \alpha=0.02, \sigma=0.01$. 
low competition country via exports. Based on these equilibrium results it can be concluded that the prevailing relative cost pattern must lie below the continuous line in panel c) as it depicts the only range of relative cost constellations for which the export mode represents a relevant entry mode.

Panel b) in figure 10 illustrates that a higher degree of competition on the alternative foreign market turns out to be accompanied by two adjustments. The first effect of an increased competition, is a decrease in both productivity cut-offs $\vartheta_{i}^{*}$. Due to the particular cost assumptions within the proximity-concentration trade-off framework the FDI mode's cut-off reduction turns out to be bigger than in the export mode with

$$
\frac{\partial \vartheta_{F}^{*}}{\partial \nu}<\frac{\partial \vartheta_{E}^{*}}{\partial \nu}<0
$$

Compliant with the general economic intuition, an investor enters the more competitive market depicted in panel b) at lower productivity levels and therefore, implicitly at an earlier expected time. However, there exists a second effect which arises in the presence of higher competition. All value functions in panel b) increase in their convexity but the rise in the FDI mode's option value turns out to be stronger than in the export mode with

$$
\frac{\partial F_{F}(\vartheta)}{\partial \nu}>\frac{\partial F_{E}(\vartheta)}{\partial \nu}>0
$$

As a consequence of the disproportionate increase of the FDI mode's option and investment values the upper envelope in panel b) is only composed of FDI related functions. Panel c) represents in a further way the stronger increase of the FDI mode's option value. The dotted curve represents all relative cost constellations in country B for which the option values of both market entry modes are equal. The continuous line represents the same relationship but corresponds to country A. Technically, a rise in the degree of competition increases the range of relative cost patterns in panel c) which enforce first time market entry through FDI. In the underlying example the investor will serve country B through a foreign plant due to the higher competition. The intuition for this second effect is as follows. Besides an earlier market entry, a higher degree of competition necessitates a higher productivity in order to survive in the market. Since the marginal costs in the FDI mode are lower than in the export mode and since their impact on the profits dominate in the long run, FDI turns out to become more likely the higher the degree of competition. 


\section{Result 7:}

For $I_{E}<I_{F}, w_{E} \tau^{\frac{1}{\theta}}>w_{F}$ and $\beta>\kappa>0$, a rise in the degree of competition (rise in $\nu$ ) decreases the expected market entry time $\mathbb{E}\left(T_{i}^{*}\right)$ and, also the optimal cut-offs $\vartheta_{i}^{*}$. Simultaneously, the likeliness of market entry through FDI increases.

Finally, table 1 summarizes the effects of remaining parameters.

\begin{tabular}{|l|c|c|c|c|c|c|}
\hline & $\begin{array}{r}\text { Probability } \\
\text { FDI Mode }\end{array}$ & $\begin{array}{c}\text { Probability } \\
\text { Export Mode }\end{array}$ & $\vartheta_{E}^{*}$ & $\vartheta_{F}^{*}$ & $\mathbb{E}\left(T_{E}^{*}\right)$ & $\mathbb{E}\left(T_{F}^{*}\right)$ \\
\hline \hline Transport Costs: $\tau \uparrow$ & $\uparrow$ & $\downarrow$ & $\uparrow$ & - & $\uparrow$ & - \\
\hline Variable Costs (Home): $w_{E} \uparrow$ & $\uparrow$ & $\downarrow$ & $\uparrow$ & - & $\uparrow$ & - \\
\hline Variable Costs (Foreign): $w_{F} \uparrow$ & $\downarrow$ & $\uparrow$ & - & $\uparrow$ & - & $\uparrow$ \\
\hline Fixed costs (Export): $I_{E} \uparrow$ & $\uparrow$ & $\downarrow$ & $\uparrow$ & - & $\uparrow$ & - \\
\hline Fixed costs (FDI): $I_{F} \uparrow$ & $\downarrow$ & $\uparrow$ & - & $\uparrow$ & - & $\uparrow$ \\
\hline
\end{tabular}

Table 1: Summary of Comparative Statics

All adjustments which appear due to marginal changes in these parameters can be derived from figure 7. An increase e.g. in transport costs $\tau$ leads to a reallocation in the relative cost space to the left which is dominated by cost constellations enforcing FDI as the optimal first time market entry mode.

Since the derived graph includes both, the parameters of dynamic aspects and static costs, it is a convenient tool to visualize the effects of uncertain productivity growth within the proximityconcentration trade-off framework and their impact on the optimal market entry mode. 


\section{Conclusion}

Whether firms serve a new foreign market through exports or horizontal FDI has become a frontier research field in international economics. Major contributions have been conducted under the umbrella of the New New Trade Theory where the seminal work by Helpman et al. (2004) paved the way for different analyses. In the tradition of international economics these models are framed as static general equilibrium models and perform empirically very well (Helpman, 2006). A major result within this strand of literature is that firms serving a foreign market through export tend to be less productive than those entering the market through horizontal FDI. Furthermore, a higher productivity dispersion within a sector seems to increase the share of FDI entrants.

One neglected aspect within these models are dynamic elements, in particular the fact that productivity growth is a continuous stochastic variable. The question e.g. whether volatile productivity growth might have a selection effect on market entry modes over time can not be answered. On the other hand from a firm perspective, productivity is a dynamic decision variable accounted for by decision takers. CEOs of multinational enterprises have certain expectations on their companies' productivity development and try to optimize their market entry modes intertemporally. Empirically, a boost in FDI could be observed especially in the mid 1980 and 1990 (UNCTAD, 2008) associated with disproportional growth in firm productivity due to information technology (IT) improvements. Given these observations and the lack of dynamic models accounting for timing effects, the underlying model elaborates market entry choice of a multinational firm. By combining the proximity-concentration trade-off framework with the real option methodology several results are derived which contribute to the existing literature. Within the assumed specific costs patterns productivity growth turns out to favor FDI as the optimal market entry strategy. The higher the productivity growth rate is the more likely is a firm to enter the new foreign market as a foreign direct investor. Since productivity growth is a volatile process (Baily et al. 2001) the model accounts for uncertainty. A riskier productivity growth turns out to increase the likeliness of market entry through FDI even further. This result coincides with the New New Trade Theory findings where sectors with a higher productivity distortion exhibit higher FDI shares. Finally the model offers the possibility to quantify the first time market entry time given an uncertain growth rate. The crucial result of the model is that both productivity growth and uncertainty increase the likeliness of market entry as foreign direct investor. 


\section{References}

Baily, Martin N., Bartelsman, Eric J., and John Haltiwanger, 2001. Labor Productivity: Structural Change And Cyclical Dynamics. The Review of Economics and Statistics, Vol. 83, No. 3, 420-433.

Bernard, Andrew B. and Jensen, Bradford J., 1995. Exporters, Jobs, and Wages in U.S. Manufacturing: 1976-1987. Brooking Papers on Economic Activity. Microeconomics, Volume $1995,67-112$.

Bloom, Nicolas, Sadun, Raffaella, and John Van Reenen 2007. Americans Do I.T. Better: US Multinationals and the Productivity Miracle. NBER Working Paper No. 13085.

Brainard, S. Lael, 1993. A simple theory of multinational corporations and trade with trade-off between proximity and concentration. NBER Working Paper No. 4269.

Brainard, S. Lael, 1997. An empirical assessment of the proximity-concentration trade-off between multinational sales. American Economic Review, Vol. 87, 520-544.

Dixit, Avinash K., 1993. The art of smooth pasting. Chur, Switzerland: Harwood academic publishers.

Dixit, Avinash K. and Pindyck, Robert S., 1994. Investment under uncertainty. Princeton: Princeton University Press.

Doms, Mark E., Jensen, Bradford J., 1998. Comparing wages, skills, and productivity between domestically and foreign owned manufacturing establishments in the united states, in Robert E. Baldwin, Robert E. Lipsey, and J. David Richardson, eds., Geography and ownership as bases for economic accounting. NBER Studies in Income and Wealth, Vol. 59, Chicago: University of Chicago Press.

Dornbusch, Rüdiger, Stanley Fischer, and Paul A. Samuelson, 1977. Comparative Ad- 
vantage, Trade, and Payments in a Ricardian Model with a Continuum of Goods. American Economic Review, Vol. 67, No. 5, 823-839.

Ethier, Wilfred, 1986. The multinational firm. Quarterly Journal of Economics, 805-833.

Ethier, Wilfred and Markusen, James R., 1996. Multinational firms, technology diffusion, and trade. Journal of International Economics, Vol. 41, 1-28.

Faggio, Giulia Salvanes and John Van Reenen, 2007. The Evolution of Inequality in Productivity and Wages: Panel Data Evidence. NBER Working Paper No. 13351.

Girma, Sourafel, Kneller, Richard, and Mauro Pisu, 2005. Export versus FDI: An Empirical Test. Review of World Economics, Vol. 141, No. 2, 193 -218.

Greenaway, David and Kneller, Richard 2007. Firm Heterogeneity, Exporting and Foreign Direct Investment: A Survey. Economic Journal, Vol. 117, 134-161.

Heckscher, Eli and Bertil Ohlin, 1991. Hecksher-Ohlin Trade Theory. Ed. Harry Flam and M. June Flanders. Cambrige: MIT Press.

Helpman, Elhanan, 1984. Simple theory of international trade with multinational corporations. Journal of Political Economy, Vol. 92, 451-471.

Helpman, Elhanan, 1985. Multinational corporation and trade structure. Review of Economic Studies, Vol. 52, 442-458.

Helpman, Elhanan, Melitz, Marc J., Yeaple, Stephen R., 2004. Export versus FDI with Heterogeneous Firms. American Economic Review, Vol. 94, 300-316.

Helpman, Elhanan, 2006. Trade, FDI, and the Organization of Firms. Journal of Economic Literature, Vol. 44, No.3, 589-630. 
Horstmann, Ignatius J. and Markusen, James R., 1987. Strategic Investment and the Development of Multinationals. International Economic Review, Vol. 28, 109-121.

Johnson, Norman L., Kotz, Samuel, and Balakrishnan, N., 1995. Continuous Univariate Distributions. 2nd edition. New York: John Wiley \& Sons, Inc.

Jorgenson, Dale W., 1963. Capital Theory and Investment Behavior. American Economic Review, Vol. 53, No. 2, 247-259.

Karatzas I. and S. Shreve, 1991. Brownian motion and stochastic calculus. 2nd edition. New York: Springer Verlag.

Karlin, Samuel and Taylor, Howard M, 1975. A First Course in Stochastic Processes. 2nd edition. New York: Academic Press.

Krugman, Paul, 1979. Increasing returns, monopolistic competition, and international trade. Journal of International Economics, Vol. 9, No. 4, 469-479.

Krugman, Paul, 1980. Scale Economies, Product Differentiation, and the Pattern of Trade. American Economic Review, Vol. 70, No. 5, 950-959.

Leslie, Keith J., Michaels, Max P., 1997. The real power of real options. The McKinsey Quarterly, No. 3, 4-22.

Markusen, James R. and Venables, Anthony J., 1998. Multinational Firms and the New Trade Theory. Journal of International Economics, Vol. 46, 183-203.

Markusen, James R. and Venables, Anthony J., 2000. The Theory of Endwoment, IntraIndustry and Multinational Trade. Journal of International Economics, Vol. 52, 209-234. 
McDonald, Robert and Siegel, Daniel R., 1986: The value of waiting to invest. Quarterly Journal of Economics, November: 101, No. 4, 707-728.

Melitz, Marc J., 2003. The Impact of Trade on Intra Industry Reallocations and Aggregate Industry Productivity. Econometrica, November: 71, Issue 6, 1695-1725.

Navaretti, Giorgio Barba and Venables, Anthony J., 2004. Multinational Firms in the World Economy. Princeton: Princeton University Press.

Pindyck, Robert S., 1991. Irreversibility, Uncertainty, and Investment. Journal of Economic Literature, Vol. 29, No. 3, 1110-48.

Ross, Sheldon M., 1996. Stochastic Processes. 2nd edition. New York: John Wiley \& Sons.

Sharpe, William F., 1964. Capital Asset Prices: A Theory of market Equilibrium under Conditions of Risk. The Journal of Finance, Vol. 19, 425-442.

Schwartz, E., S., Trigeorgis, L., 2004 Real Options and Investment under Uncertainty. Classical Readings and Recent Contributions, Massachusetts: The MIT Press.

UNCTAD, 2008. World investment report 2008. New York and Geneva: United Nations.

Yeaple, Stephen, 2008. Firm Heterogeneity and the Structure of U.S. Multinational Activity: An Empirical Analysis. NBER Working Paper No. 14072.

Wagner, Joachim, 2006. Exports, foreign direct investment, and productivity: evidence from German firm level data. Applied Economics Letters, Vol. 13, 347-349.

Wong, Kit P., 2007. The effect of uncertainty on investment timing in a real options model. Journal of Economic Dynamics and Control, Vol. 31, 2152-2167. 


\section{CESifo Working Paper Series}

for full list see www.cesifo-group.org/wp

(address: Poschingerstr. 5, 81679 Munich, Germany, office@cesifo.de)

2709 Jon H. Fiva and Gisle James Natvik, Do Re-election Probabilities Influence Public Investment?, July 2009

2710 Jarko Fidrmuc and Iikka Korhonen, The Impact of the Global Financial Crisis on Business Cycles in Asian Emerging Economies, July 2009

2711 J. Atsu Amegashie, Incomplete Property Rights and Overinvestment, July 2009

2712 Frank R. Lichtenberg, Response to Baker and Fugh-Berman's Critique of my Paper, "Why has Longevity Increased more in some States than in others?", July 2009

2713 Hans Jarle Kind, Tore Nilssen and Lars Sørgard, Business Models for Media Firms: Does Competition Matter for how they Raise Revenue?, July 2009

2714 Beatrix Brügger, Rafael Lalive and Josef Zweimüller, Does Culture Affect Unemployment? Evidence from the Röstigraben, July 2009

2715 Oliver Falck, Michael Fritsch and Stephan Heblich, Bohemians, Human Capital, and Regional Economic Growth, July 2009

2716 Wladimir Raymond, Pierre Mohnen, Franz Palm and Sybrand Schim van der Loeff, Innovative Sales, R\&D and Total Innovation Expenditures: Panel Evidence on their Dynamics, July 2009

2717 Ben J. Heijdra and Jochen O. Mierau, Annuity Market Imperfection, Retirement and Economic Growth, July 2009

2718 Kai Carstensen, Oliver Hülsewig and Timo Wollmershäuser, Price Dispersion in the Euro Area: The Case of a Symmetric Oil Price Shock, July 2009

2719 Katri Kosonen and Gaëtan Nicodème, The Role of Fiscal Instruments in Environmental Policy, July 2009

2720 Guglielmo Maria Caporale, Luca Onorante and Paolo Paesani, Inflation and Inflation Uncertainty in the Euro Area, July 2009

2721 Thushyanthan Baskaran and Lars P. Feld, Fiscal Decentralization and Economic Growth in OECD Countries: Is there a Relationship?, July 2009

2722 Nadia Fiorino and Roberto Ricciuti, Interest Groups and Government Spending in Italy, 1876-1913, July 2009

2723 Andreas Wagener, Tax Competition, Relative Performance and Policy Imitation, July 2009 
2724 Hans Fehr and Fabian Kindermann, Pension Funding and Individual Accounts in Economies with Life-cyclers and Myopes, July 2009

2725 Ernesto Reuben and Arno Riedl, Enforcement of Contribution Norms in Public Good Games with Heterogeneous Populations, July 2009

2726 Kurt Schmidheiny and Marius Brülhart, On the Equivalence of Location Choice Models: Conditional Logit, Nested Logit and Poisson, July 2009

2727 Bruno S. Frey, A Multiplicity of Approaches to Institutional Analysis. Applications to the Government and the Arts, July 2009

2728 Giovanni Villani, A Strategic R\&D Investment with Flexible Development Time in Real Option Game Analysis, July 2009

2729 Luca Di Corato and Michele Moretto, Investing in Biogas: Timing, Technological Choice and the Value of Flexibility from Inputs Mix, July 2009

2730 Gilad D. Aharonovitz, Nathan Skuza and Faysal Fahs, Can Integrity Replace Institutions? Theory and Evidence, July 2009

2731 Michele Moretto and Sergio Vergalli, Managing Migration through Conflicting Policies: an Option-theory Perspective, July 2009

2732 Volker Nitsch, Fly or Cry: Is Airport Noise Costly?, July 2009

2733 Francesco Cinnirella and Joachim Winter, Size Matters! Body Height and Labor Market Discrimination: A Cross-European Analysis, July 2009

2734 Samuel Bowles and Sandra Polanía Reyes, Economic Incentives and Social Preferences: A Preference-based Lucas Critique of Public Policy, July 2009

2735 Gary Burtless, Lessons of the Financial Crisis for the Design of National Pension Systems, July 2009

2736 Helmuth Cremer, Firouz Gahvari and Pierre Pestieau, Fertility, Human Capital Accumulation, and the Pension System, July 2009

2737 Hans Jarle Kind and Frank Stähler, Market Shares in Two-Sided Media Industries, July 2009

2738 Pamela Campa, Alessandra Casarico and Paola Profeta, Gender Culture and Gender Gap in Employment, August 2009

2739 Sebastian Gechert, Supplementary Private Health Insurance in Selected Countries: Lessons for EU Governments?, August 2009

2740 Leif Danziger, Endogenous Monopsony and the Perverse Effect of the Minimum Wage in Small Firms, August 2009 
2741 Yan Dong and John Whalley, A Third Benefit of Joint Non-OPEC Carbon Taxes: Transferring OPEC Monopoly Rent, August 2009

2742 Valentina Bosetti, Carlo Carraro and Massimo Tavoni, Climate Change Mitigation Strategies in Fast-Growing Countries: The Benefits of Early Action, August 2009

2743 Christina Felfe, The Willingness to Pay for Job Amenities: Evidence from Mothers' Return to Work, August 2009

2744 Jörg Franke, Christian Kanzow, Wolfgang Leininger and Alexandra Väth, Effort Maximization in Asymmetric N-Person Contest Games, August 2009

2745 Bruno S. Frey and Paolo Pamini, Making World Heritage Truly Global: The Culture Certificate Scheme, August 2009

2746 Frank N. Caliendo, Is Social Security behind the Collapse of Personal Saving?, August 2009

2747 Caterina Liesegang and Marco Runkel, Corporate Income Taxation of Multinationals and Fiscal Equalization, August 2009

2748 Chrysovalantou Milliou and Apostolis Pavlou, Upstream Horizontal Mergers and Efficiency Gains, August 2009

2749 Rüdiger Pethig and Christian Wittlich, Interaction of Carbon Reduction and Green Energy Promotion in a Small Fossil-Fuel Importing Economy, August 2009

2750 Kai Carstensen, Oliver Hülsewig and Timo Wollmershäuser, Monetary Policy Transmission and House Prices: European Cross-country Evidence, August 2009

2751 Olaf Posch, Explaining Output Volatility: The Case of Taxation, August 2009

2752 Beatrice Scheubel, Daniel Schunk and Joachim Winter, Don't Raise the Retirement Age! An Experiment on Opposition to Pension Reforms and East-West Differences in Germany, August 2009

2753 Daniel G. Arce, Dan Kovenock and Brian Roberson, Suicide Terrorism and the Weakest Link, August 2009

2754 Mario Larch and Wolfgang Lechthaler, Comparative Advantage and Skill-Specific Unemployment, August 2009

2755 Horst Raff and Nicolas Schmitt, Buyer Power in International Markets, August 2009

2756 Seppo Kari, Hanna Karikallio and Jukka Pirttilä, The Impact of Dividend Taxation on Dividends and Investment: New Evidence Based on a Natural Experiment, August 2009

2757 Mirco Tonin and Michael Vlassopoulos, Disentangling the Sources of Pro-social Behavior in the Workplace: A Field Experiment, August 2009 
2758 Nicole Grunewald and Inmaculada Martínez-Zarzoso, Driving Factors of Carbon Dioxide Emissions and the Impact from Kyoto Protocol, August 2009

2759 Yu-Fu Chen and Michael Funke, Booms, Recessions and Financial Turmoil: A Fresh Look at Investment Decisions under Cyclical Uncertainty, August 2009

2760 Jan-Egbert Sturm and Jakob de Haan, Does Central Bank Communication really Lead to better Forecasts of Policy Decisions? New Evidence Based on a Taylor Rule Model for the ECB, August 2009

2761 Larry Karp, Sacrifice, Discounting and Climate Policy: Five Questions, August 2009

2762 Marianna Belloc and Samuel Bowles, International Trade, Factor Mobility and the Persistence of Cultural-Institutional Diversity, August 2009

2763 Charles Noussair and Fangfang Tan, Voting on Punishment Systems within a Heterogeneous Group, August 2009

2764 Birgit Bednar-Friedl and Karl Farmer, Internationally Coordinated Emission Permit Policies: An Option for Withdrawers from the Kyoto Protocol?, August 2009

2765 Pierre M. Picard and David E. Wildasin, Labor Market Pooling, Outsourcing and Labor Contracts, August 2009

2766 Stefan Voigt and Lorenz Blume, The Economic Effects of Federalism and Decentralization - A Cross-Country Assessment, August 2009

2767 David S. Jacks, Christopher M. Meissner and Dennis Novy, Trade Booms, Trade Busts, and Trade Costs, August 2009

2768 Mario Jametti and Thomas von Ungern-Sternberg, Hurricane Insurance in Florida, August 2009

2769 Alessandro Balestrino, Kind of Black: The Musicians' Labour Market in Italy, August 2009

2770 Yosr Abid Fourati and Cathal O’Donoghue, Eliciting Individual Preferences for Pension Reform, August 2009

2771 Christian Breuer and Chang Woon Nam, VAT on Intra-Community Trade and Bilateral Micro Revenue Clearing in the EU, August 2009

2772 Choudhry Tanveer Shehzad, Jakob De Haan and Bert Scholtens, Growth and Earnings Persistence in Banking Firms: A Dynamic Panel Investigation, August 2009

2773 Erdal Yalcin, Uncertain Productivity Growth and the Choice between FDI and Export, August 2009 